Portland State University

PDXScholar

\title{
An Examination of Limiting Factors of Chrysemys picta bellii (Western painted turtles) in the Lower Willamette River Basin, Oregon
}

James P. Holley

Portland State University

Follow this and additional works at: https://pdxscholar.library.pdx.edu/mem_gradprojects

Part of the Animal Sciences Commons, Environmental Indicators and Impact Assessment Commons, Environmental Monitoring Commons, and the Natural Resources Management and Policy Commons Let us know how access to this document benefits you.

\section{Recommended Citation}

Holley, James P., "An Examination of Limiting Factors of Chrysemys picta bellii (Western painted turtles) in the Lower Willamette River Basin, Oregon" (2021). Environmental Science and Management Professional Master's Project Reports. 71.

https://pdxscholar.library.pdx.edu/mem_gradprojects/71

https://doi.org/10.15760/mem.74

This Project is brought to you for free and open access. It has been accepted for inclusion in Environmental Science and Management Professional Master's Project Reports by an authorized administrator of PDXScholar. Please contact us if we can make this document more accessible: pdxscholar@pdx.edu. 
An Examination of Limiting Factors of Chrysemys picta bellii (Western painted turtles) in the Lower Willamette River Basin, Oregon

by

James P. Holley

A thesis submitted in partial fulfillment of the requirements for the degree of

Master of Environmental Management

Committee:

Dr. Catherine de Rivera

Dr. Sarah Carvill

Susan Barnes

Laura Guderyahn

Portland State University

2021 


\section{Table of Contents}

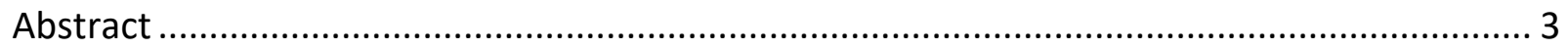

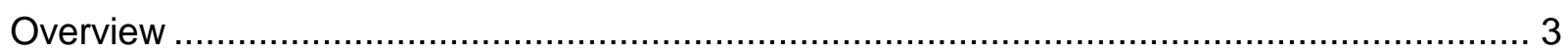

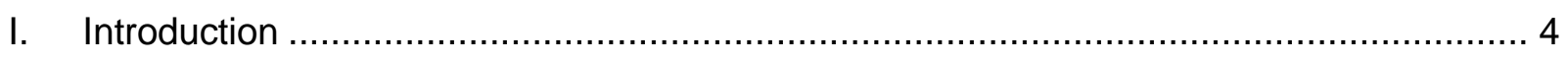

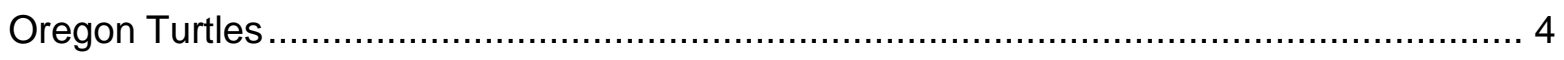

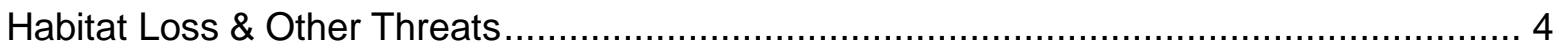

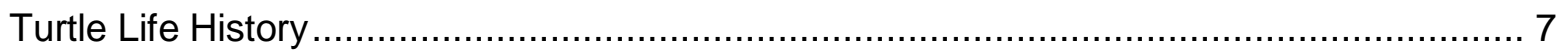

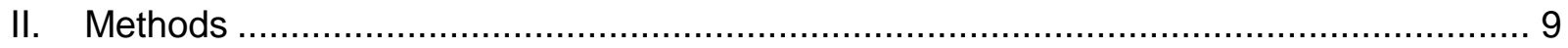

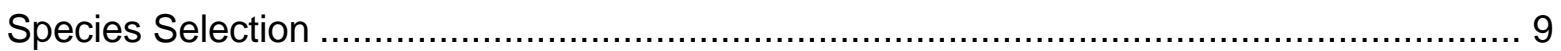

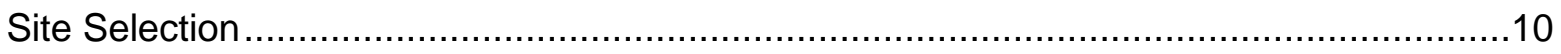

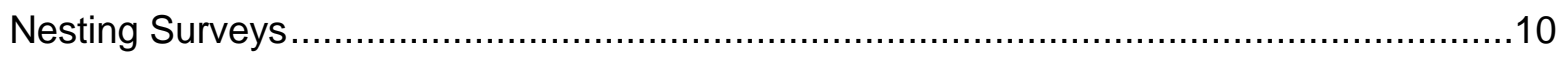

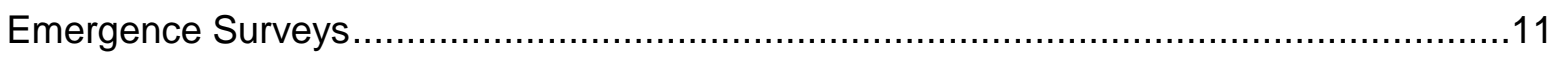

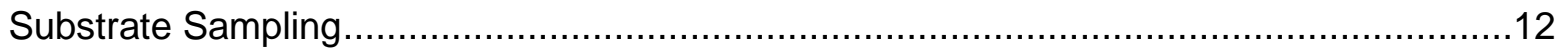

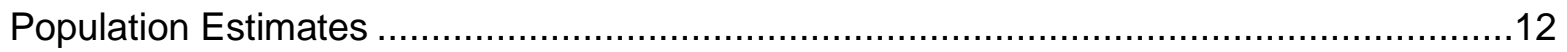

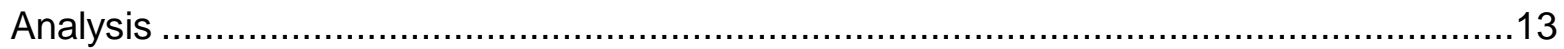

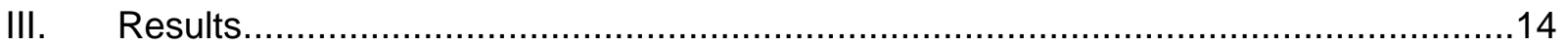

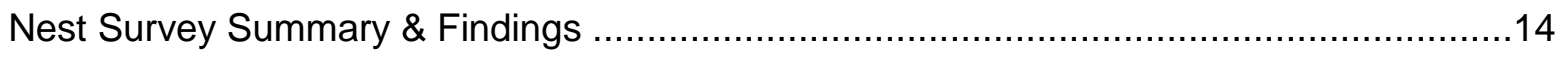

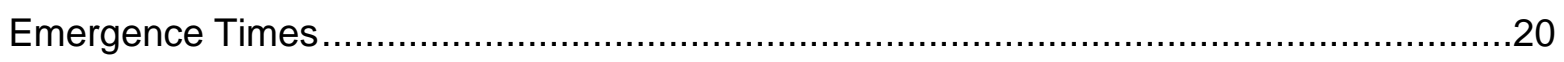

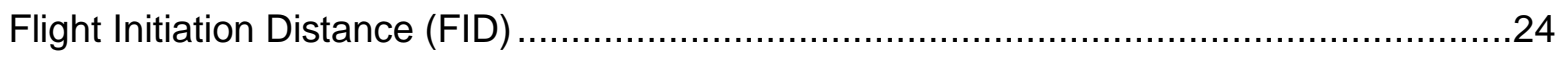

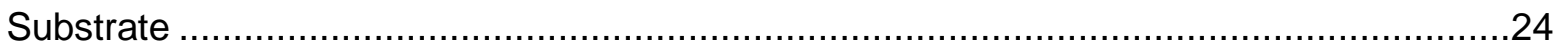

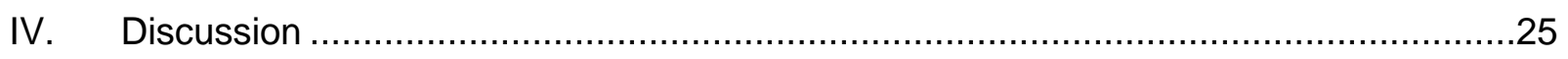

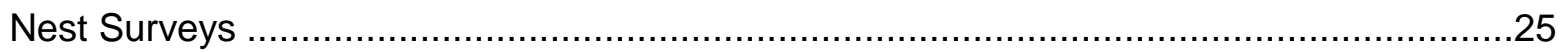

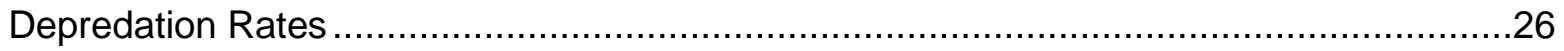

Human Impacts on Turtle Nesting and Population Size ...........................................27

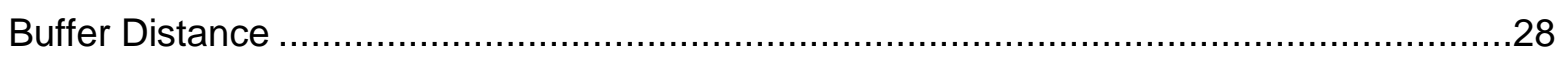

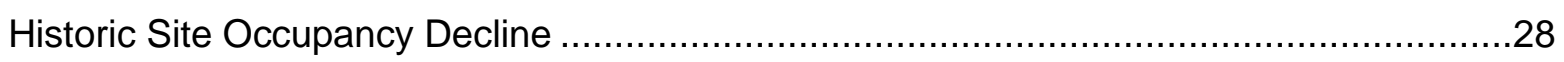

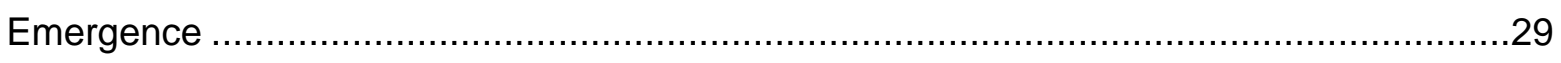

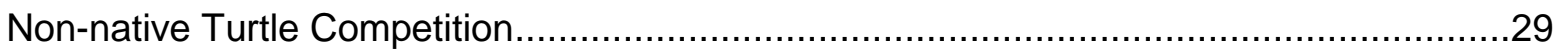

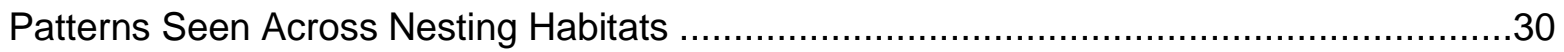

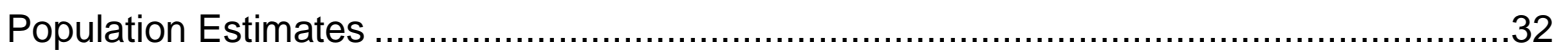

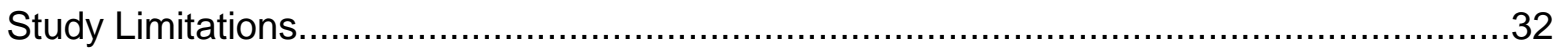

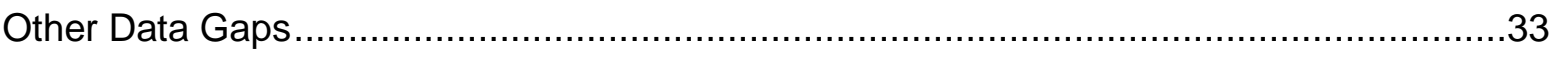




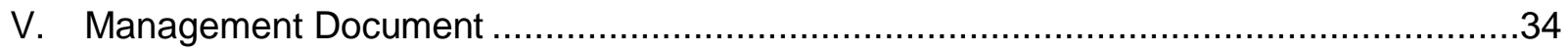

Turtle Habitat Summary \& Management Recommendations ..........................................34

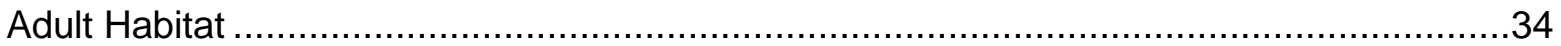

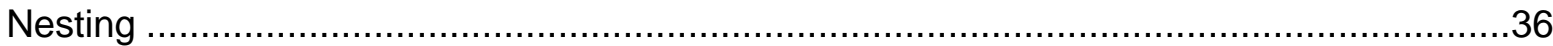

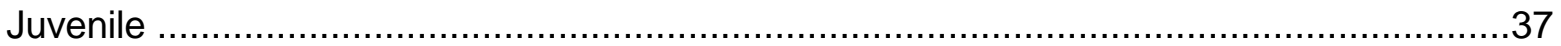

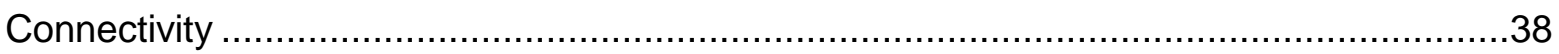

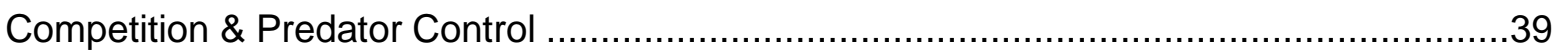

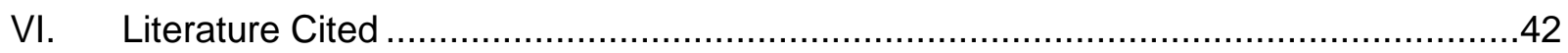

Appendix A: Original protocol used for May 2019 volunteer trainings...............................46

Appendix B: Aquatic Complexity Surveys \& Methods ..................................................

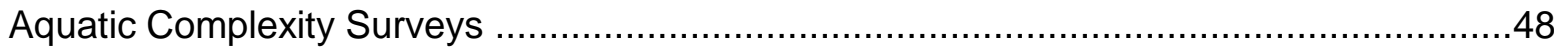

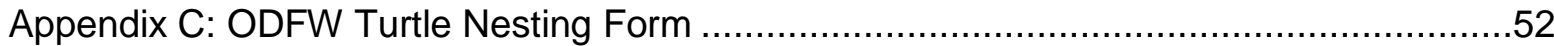

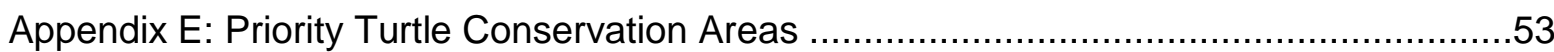

Appendix F Priority Turtle Conservation Areas .......................................................54 


\section{Abstract}

Oregon's two native freshwater turtle species, Chrysemys picta bellii (Western painted turtle) and Actinemys marmorata (Northwestern pond turtle), have seen significantly reduced population sizes since the founding of Portland in 1845, with estimates of up to $90 \%$ for A. marmorata. This project examined turtle nesting activity at 25 sites across a range of turtle populations and habitats around the Lower Willamette River Basin. All discovered turtle nesting activity was found in areas of high solar exposure. We found $93 \%$ of over 400 nest attempts to have been depredated across the 25 sites, well above most other reported rates. At several sites, many aborted nest attempts were found atop gravel roadbeds, indicating that lack of appropriate substrate is potentially limiting nesting success. The presence of greater than five pedestrians per hour at turtle nesting areas was correlated with a substantial decrease in nesting attempts suggesting that management of recreational activities may play a role in the amount of nesting activity occurring. Hence, sitespecific solutions, such as importing substrate, alteration of path locations or seasonal trail closures to lessen human foot traffic disturbance of turtle nesting attempts, are likely to improve recruitment rates of native turtles in the Lower Willamette Basin. Further studies that improve knowledge of population demographics, the impact of human activities on turtles, and habitat needs of juvenile turtles are needed to support long-term self-sustaining turtle populations.

\section{Overview}

While turtle sightings in the Portland Metro region are not a rarity, the longevity of these turtle species may delay a clear understanding of the extent of the many threats Oregon turtles face due to habitat loss and other anthropogenic pressures (Swihart, 2006). Lack of ample nesting and/or juvenile habitat in proper relation to one another could limit future recruitment of young animals that may not be noticed for decades as adult turtles continue to live out their 50+ year life spans (Bury, et al. 2012). If lack of population recruitment is as widespread as worst-case scenarios imagine, more native turtle populations could be extirpated in coming decades (Gibbons et al., 2000).

This document provides an overview of the study, including methods, key results, and a discussion of the interpretation of the results as they apply to management. The goal of this project was to fill gaps in the literature on the factors limiting native turtle population size, particularly the nesting and juvenile life stages.

NOTE: Specific site names have not been used in this report to protect against collection of native turtle species for food and the pet trade. Oregon's two native turtle species are regulated as Protected Nongame Wildlife by Oregon Administrative Rule 635-044. 


\section{Introduction}

Chrysemys picta bellii (Western painted turtle) and Actinemys marmorata (Northwestern pond turtle) populations have been reduced in Oregon since Portland became a city in 1845 . The primary cause of decline is loss of preferred lentic floodplain habitat due to the widespread implementation of anthropogenic flood control measures (ODFW, 2015) (Figures 1 \& 2). Recent visual encounter surveys documented current turtle distributions with a notable lack of observed age class diversity throughout the study area. The Oregon Native Turtle Working Group, Lower Willamette Chapter (ONTWG) has identified lack of population recruitment to be a major threat to the long-term persistence of Oregon's native turtle species (ODFW, 2015). This project aimed to better understand the limiting factors surrounding population recruitment, focusing on $C$. picta bellii.

\section{Oregon Turtles}

C. picta bellii is one of four subspecies of painted turtle in North America with its westernmost distribution following the Columbia River west across the northern border of Oregon. It is the most prevalent turtle in the state north of Salem, dominating the prime complex habitat found at the confluence of the Willamette and Columbia Rivers. A. marmorata is the only native turtle found in the southern portion of the state, where it utilizes lentic habitat and has also adapted to thrive in lotic habitat of large river systems. A. marmorata has a higher tolerance for flowing water than C. picta bellii with populations inhabiting lotic systems of fourth order streams and higher in the Tualatin, Yamhill, McKenzie, Santiam, Luckiamute, Umpqua, Coquille, and Rogue Rivers, in addition to off-channel lentic habitat. Its extreme northern distribution extends into Washington state and once extended into British Columbia (now extirpated), but the bulk of the population resides south of Salem, Oregon through Central California. Both species are also found in small populations scattered around Eastern Oregon. Painted turtles are one of the most broadly studied species of turtle, but most of the research has been performed on populations east of the Rocky Mountains.

\section{Habitat Loss \& Other Threats}

Since the species was first described in 1848, estimates of up to $90 \%$ declines in A. marmorata populations were made by Holland (1994). Similar rates of population decline can be assumed for $C$. picta bellii as its range in the northern portion of the state has been impacted by higher rates of development than the bulk of the range of A. marmorata throughout Southwestern Oregon. Since its founding, Oregon's largest city, Portland, has experienced multiple flood events damaging property and causing loss of human life, most notably, the Vanport Flood on May 30, 1948. Dams, levees, canals, and other flood control measures have been installed to manage high water events, improve agricultural production, and harness hydraulic power. These 
steps have resulted in an overall simplification of most river systems with the state of Oregon having lost $38 \%$ of its original wetlands, the Willamette Valley experiencing a 57\% wetland loss, and an estimated 50\% loss of floodplain habitat in the Portland Metro Area (Figures $1 \& 2$ ) (Morlan, 2000).

In 2011, the ONTWG began 8 years of basin focused visual encounter surveys (VES) to gather data on the current distribution of turtles in the Lower Willamette Valley (Figure 3). Highly fragmented remnant off-channel habitats sustain some turtle populations, but continued declines have caused both turtle species to be included on Oregon's Sensitive Species List as SensitiveCritical (ODFW 2021) and identified as Species of Greatest Conservation Need in Oregon's State Wildlife Action Plan, the Oregon Conservation Strategy (ODFW, 2016). A consistent finding throughout the ONTWG surveys was a distinct lack of age class diversity, particularly lacking in observed younger age classes $(<120 \mathrm{~mm}$ carapace length). The study design of the VES is biased towards discovering adult turtles which are larger and less vulnerable than juvenile age classes, however, the potential of a widespread lack of population recruitment exists within these long-lived species.

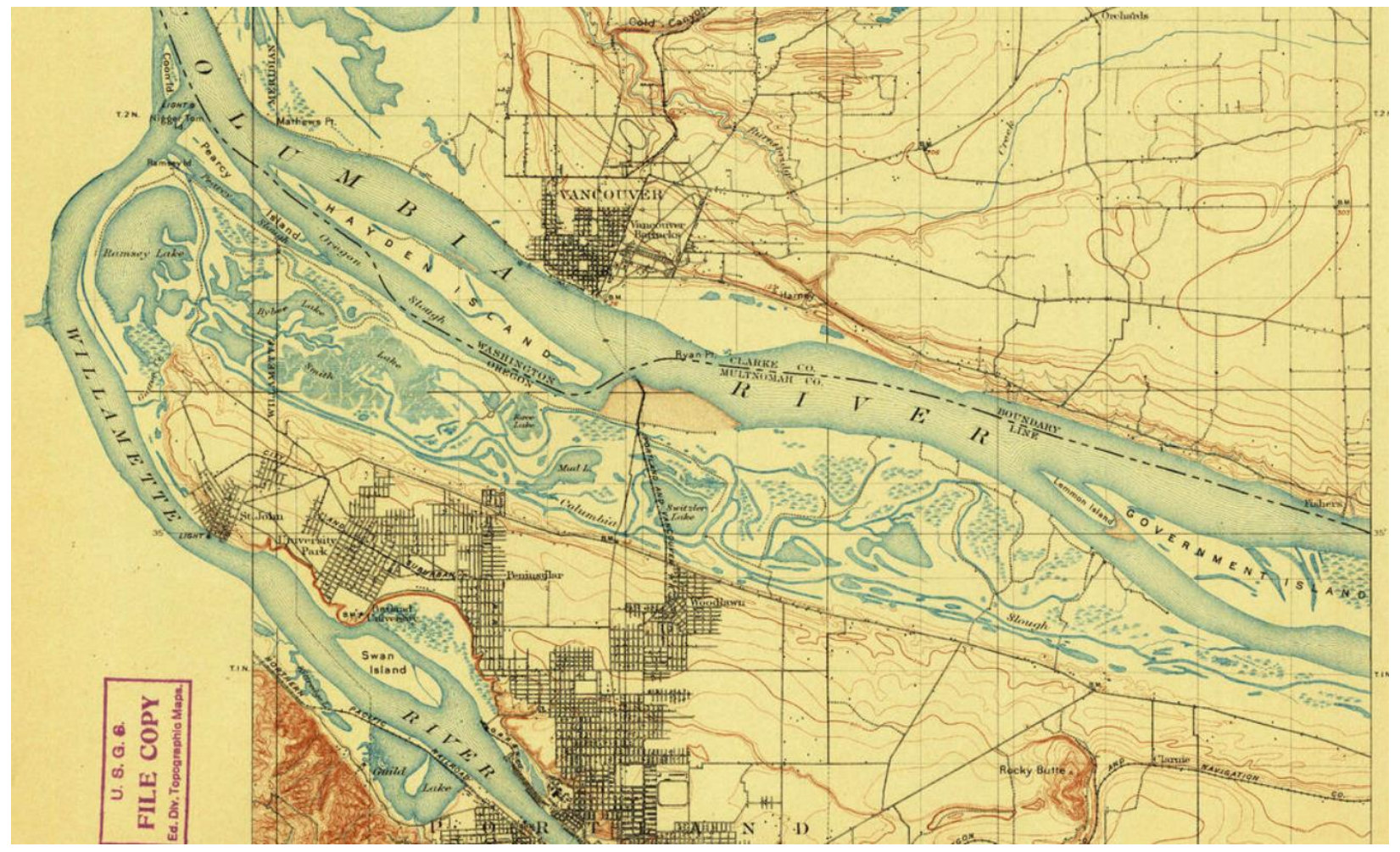

Figure 1: United States Geological Survey topographic map of Portland, Oregon, 1897. 


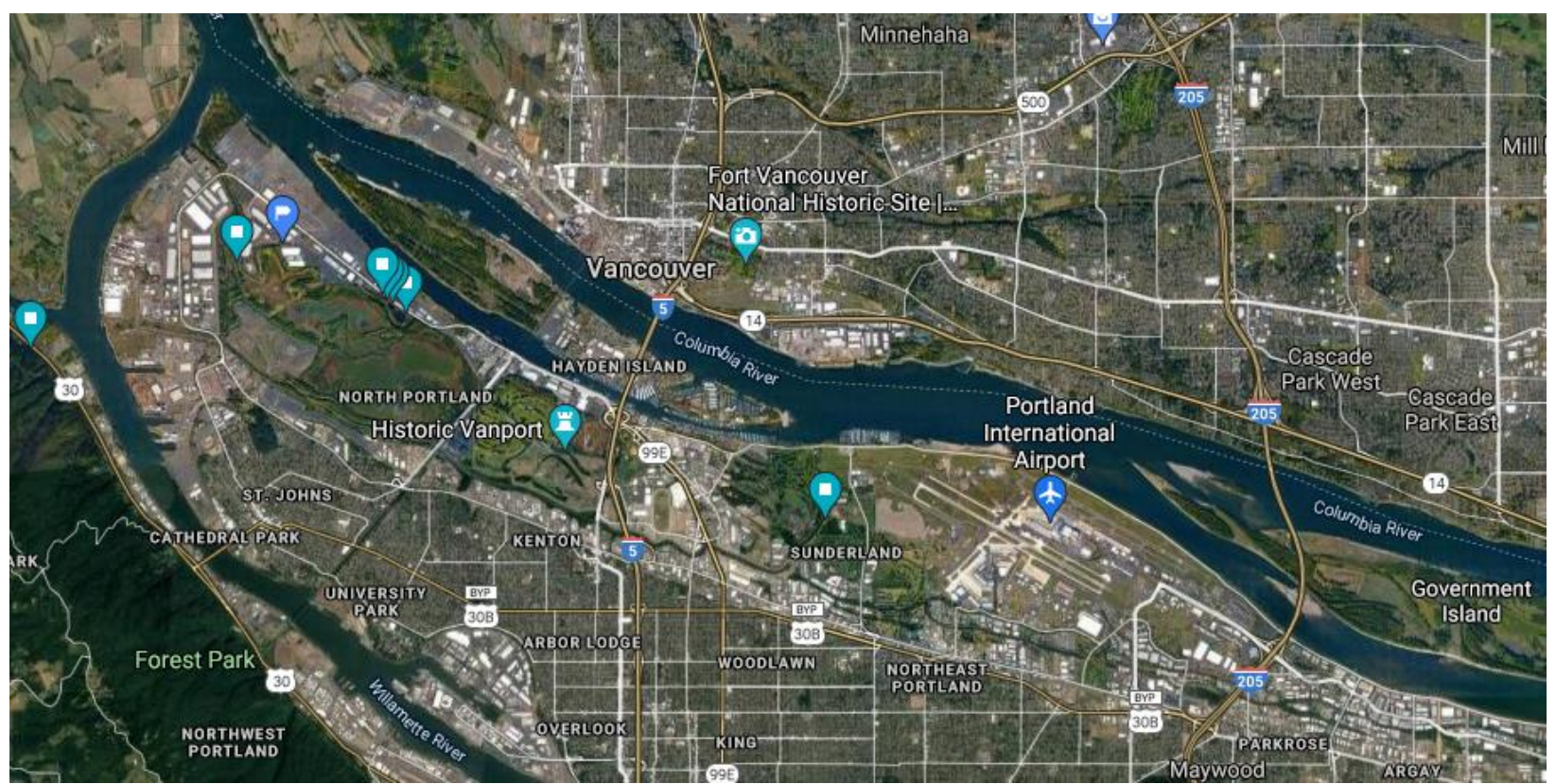

Figure 2: Google map screenshot of Portland, Oregon June 2021.

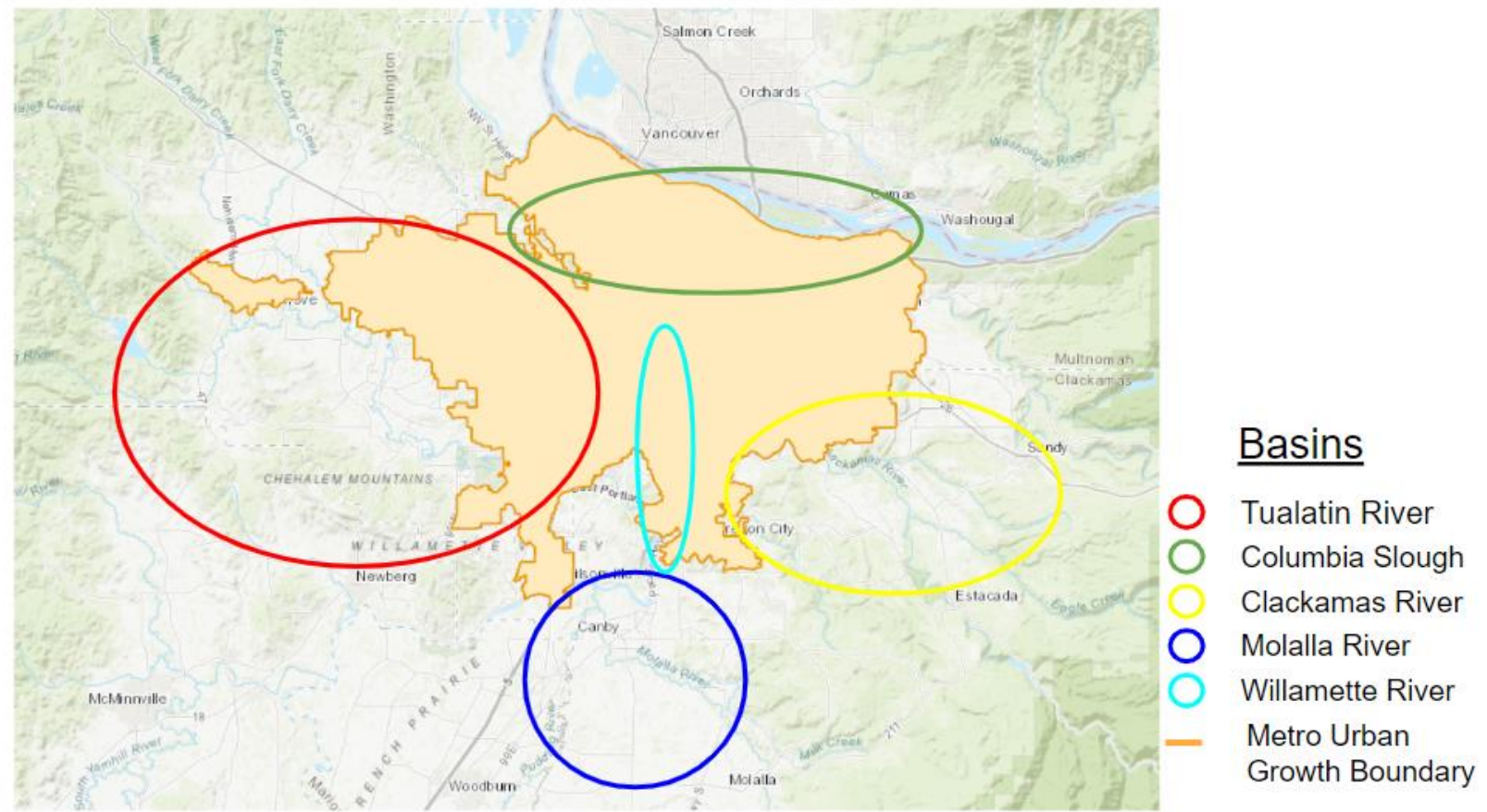

Figure 3: Lower Willamette Valley study area.

Another major threat to the long-term existence of turtles in Oregon is competition from introduced non-native species. Trachemys scripta elegans, Red-eared slider, is a common pet turtle native to the Southeastern United States. It uses similar habitat and resources as C. picta and A. marmorata, but more efficiently (Lambert et al., 2019). T. scripta elegans has been shown to dominate prime basking sites, have larger clutch sizes, and shorter brumation periods (Cadi, 2003; S. Barnes pers. obs.). The Common snapping turtle (Chelydra serpentina) is known to 
consume young turtles of other species. Both of these introduced species have established breeding populations in the state (ODFW, 2015).

\section{Turtle Life History}

Both Oregon freshwater turtle species are ectothermic and share considerable overlap in their habitat needs. Broadly, they are aquatic creatures that require nearly perennial waterbodies with areas of low to no flow velocity with areas of high solar exposure to bask. Aquatic vegetation and wood complexity are critical for shelter, food, and basking, with particular needs specific to juvenile turtles under $10 \mathrm{~cm}$ who experience high mortality rates ranging from $24-44 \%$ per year in both second and third year for painted turtles (Parrott et al, 2010). Also important for the longterm persistence of source populations is connectivity to a mosaic of aquatic and terrestrial habitats essential for necessary life processes such as nesting, summer aestivation, overwintering, and migration (Baldwin et al., 2004). The months from February through October are used by $C$. picta bellii and A. marmorata to bask, feed, and complete metabolic processes necessary for reproduction and survival (Congdon et al., 1982) (Figure 4). Some of these processes include: metabolizing food, fighting disease, gaining energy for movement and mating, maturation of eggs and sperm, and storing fat for brumation periods (Hammond et al., 1988; Carrière et al., 2008; Boyer, 1965).

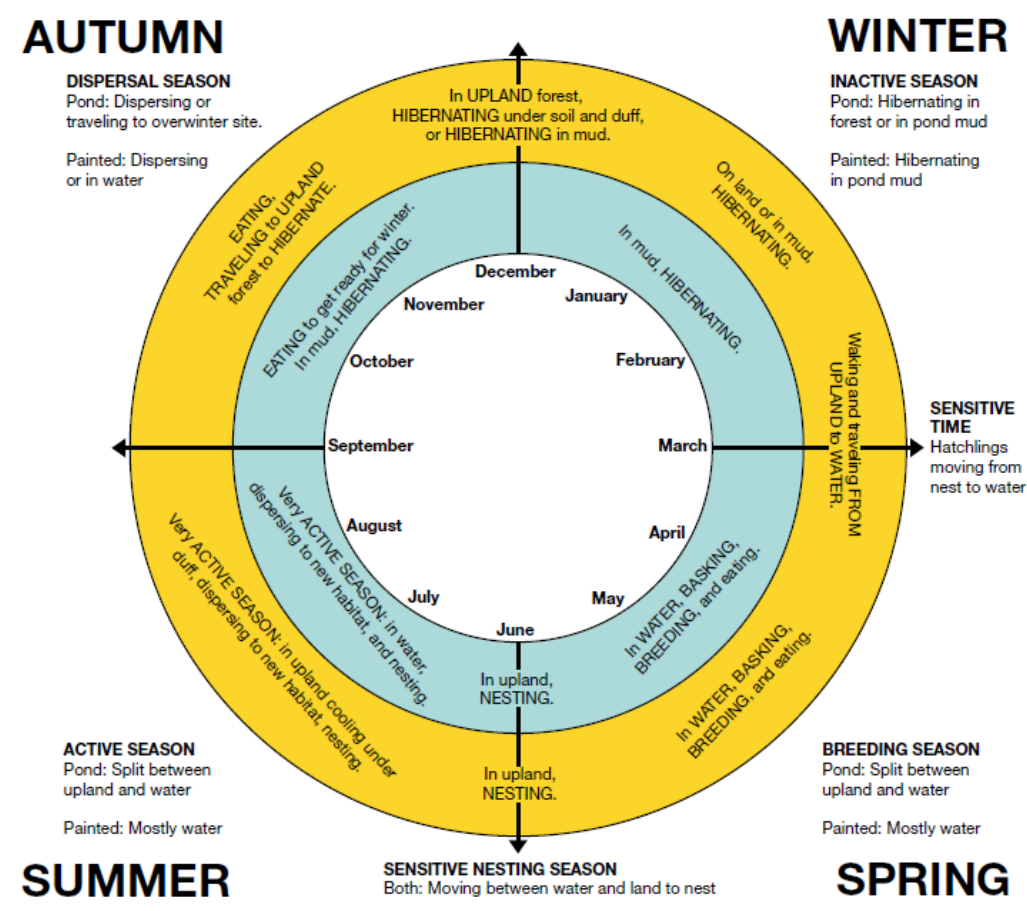

Figure 4: Annual Activity Cycle of Oregon's Native Turtles. (ODFW, 2015) 


\section{Adult}

Animals are considered adult turtles when they reach sexual maturity, usually about four years old for Western painted turtle males and seven for Western painted turtle females, but is best measured by a carapace length of more than $10 \mathrm{~cm}$ when they are less easily consumed by most predators and survival rates increase (Gibbons, 1968a; Wilson et al., 2003; Parrott et al., 2010). Adult painted turtles have high survival rates and individuals can live at least 30 years in the wild (Parrott et al., 2010). Individual Northwestern pond turtles are known to live over 50 years in the wild (Bury et al., 2012).

As ectotherms, turtles require ample time to bask to fulfill their metabolic needs. Flight initiation distance (FID), a measure of how close a perceived predator or threat can get to an animal before they alter their behavior, varies across habitats and the stimuli local turtle populations have become accustomed to. A study in Illinois on painted turtles found that urban populations allow potential threats (humans and dogs) to get within about $40 \mathrm{~m}$ before moving away, whereas rural populations disrupt their basking activities at about 60m (Pollack et al., 2016). Without a sufficient buffer to comfortably complete their life processes, long-term health and energy costs can mount (Heppard, 2018).

\section{Juvenile}

The least well understood portion of a turtle's life history is its juvenile stage, including hatchlings, usually defined as the period of time in which young turtles have a carapace length of $5-10 \mathrm{~cm}$, roughly translating to their second and third years. Their small size makes them optimum prey for a wide array of predators, including the non-native American bullfrog (Lithobates catesbeianus), raccoon (Procyon lotor), and great blue heron (Ardea herodias); necessitating a cryptic lifestyle (Hays et al., 1999). Relatively little is known about juvenile turtles specific habitat preferences due to the difficulty of capture and elusive lifestyle. Their small size allows them to pass through the mesh in most traps and avoid visual detection at a higher rate than adult turtles (Congdon et al., 1994; Rosenberg, 2013). Estimates on juvenile painted turtle survival rates vary broadly ranging from 0.46-0.82 (Parrott et al., 2010). Complex microhabitat, composed of small woody debris and aquatic vegetation, likely provides shelter and food crucial until juvenile turtles have grown. This habitat is naturally formed in floodplains of the lower sections of large river systems. These off-channel areas have largely disappeared from modern, simplified large river systems in Oregon due to flood control efforts.

\section{Nesting}

C. picta bellii and A. marmorata in Oregon most often nest in June and July, allowing hot summer temperatures to incubate their nests. In both turtle species, female turtles most often emerge from aquatic habitat between the hours of $1600(4 \mathrm{pm})$ and 0000 (midnight) to dig a flask-shaped hole about $15 \mathrm{~cm}$ deep using the full length of their hind legs (Frye et al., 2017; Holley pers. obs.). Factors involved in nest site selection for both painted and pond turtles are not 
known for certain, but nest attempts most often occur in areas of high solar exposure. Vegetation is typically sparse with areas of bare ground often present. The distance the female travels from water may be influenced by the presence or absence of particular predators (Reinsche et al., 2019; Spencer, 2006). Nests are usually dug within $100 \mathrm{~m}$ of water, but can be up to $1500 \mathrm{~m}$ from water (Delaney et al, 2016; L. Guderyahn, pers. comm.). When a C. picta bellii or A. marmorata female selects a suitable site, she urinates on the substrate, excavates the nest, and deposits her eggs, 4-16 for $C$. picta bellii and 2-13 for A. marmorata (Murphy et al., 2020; Bury et al., 2008). She will fill the hole and tamp it down leaving little evidence visible after the urine dries. $C$. picta bellii eggs incubate for 72-80 days and hatch in late summer/early autumn (Ratterman et al., 1989). In Oregon and other Northern latitudes, hatchlings of many turtle species are most likely to overwinter in the nest and emerge in spring, but autumn emergence is not uncommon (Mitchell et al., 2019).

Reported nest depredation rates of $C$. picta across its range vary from 33-92\% (Congdon et al, 1987; Parrott et al, 2010), but few studies have been performed focusing on urban populations or in the Pacific Northwest. Frequently, nests are clustered in close proximity to one another and mesopredators are able to find and prey upon many nests in succession. An experimental study published in 2004 by Marchand and Litvaitis determined that scattered nests distant from pond habitat $(100-150 \mathrm{~m})$ had lower rates of depredation than nests clustered and close to ponds $(<50 \mathrm{~m})$. A range of mesopredators have been shown to be responsible for depredating turtle nests in the region, including raccoons, skunks (Mephitis mephitis), Virginia opossums (Didelphis virginia), and coyotes (Canis latrans) (Hays et al., 1999). Populations of mesopredators are known to increase in the absence of apex predators, as is the case in most urban areas (Ritchie et al., 2009).

\section{Methods}

The primary purpose of this project was to gather baseline data on nesting activity, available nesting habitat, and limiting factors on turtle populations across a range of conditions and sites in the Lower Willamette Basin. Sites across five basins in the Portland Metro area were selected with a range in population size from 2-200+ across a spectrum of lentic habitats and resource management types.

\section{Species Selection}

C. picta bellii is the dominant native turtle species in the Lower Willamette River study area and was the focus species of this study. A. marmorata also inhabits the region but is present at a minority of the 25 study sites. Established reproducing populations of non-native T. scripta elegans were present at a majority of the sites. As most nests were identified after the turtle had returned to the aquatic environment the turtle species of most nests was not known in this study. The nests and eggshells of C. picta bellii, A. marmorata, and T. scripta elegans are quite similar 
and were grouped together for analysis in this study. C. serpentina also has established breeding populations in the study area, but their breeding habits, nest site selection, and egg characteristics differ considerably from turtles native to Oregon and their nests were excluded from this study.

\section{Site Selection}

Sites in the Lower Willamette Basin known to have been occupied by at least two individual native turtles within the past ten years (as demonstrated by ONTWG data) were selected for turtle nesting surveys. Estimated minimum native turtle populations at each site ranged between 2 and 200 individuals within five basins: Columbia Slough, Tualatin River, Clackamas River, Molalla River, and the mainstem Willamette River (Figure 3). Sites were designated as urban or rural based on their location relative to the Metro Urban Growth Boundary (UGB), with a lone exception where the site was within the UGB and considered rural due to the lower development density and high connectivity to other habitats relative to sites categorized as urban.

\section{Nesting Surveys}

Nesting surveys were conducted in June and July 2019 across the 25 selected sites in the Lower Willamette Basin. Survey times of day ranged from 0600 to 2200, but were most frequently conducted in the late morning and early evening hours. Areas with features of nesting habitat potential were identified at each site prior to the turtle nesting season. Features of appropriate nesting habitat include high solar exposure, sparse vegetation, and proximity to aquatic turtle habitat. The targeted prime nesting habitat areas at each site ranged in size from $100 \mathrm{~m}^{2}$ to 2000 $\mathrm{m}^{2}$. Areas within $30 \mathrm{~m}$ of wetland edges were targeted as the bulk of turtle nesting activity generally occurs close to the waterbody (Baldwin et al., 2004). This focal area was also frequently the limit of easily available nesting habitat at urban sites due to anthropogenic barriers such as fences, walls, and roads. More distant areas with appropriate habitat features were also explored as time and access allowed. Areas of dense vegetation and high canopy cover were also inspected to minimize surveyor bias. In order to prevent any unnecessary cueing to predators, surveyors did not mark any nests discovered before they were caged, recording only GPS coordinates. GPS points were recorded redundantly, taking a point for each turtle nest site during each survey.

Over 50 volunteers were trained to identify signs of turtle nesting activity and assist with the survey efforts. Surveyors walked in a grid pattern searching for nests with approximately two meters between surveyors to methodically cover the areas of greatest nesting potential. GPS coordinates were recorded when evidence of turtle nesting activity was detected. Conditions varied among sites with terrain and vegetation taken into account to modify search patterns in order to ensure all signs of turtle nesting activity would be observed. When possible, surveys were conducted when the ground was dry to allow greater opportunity to see signs of nesting activity such as wet spots from females urinating at nest sites and fresh excavations of 
depredated nests which are more easily observed under dryer conditions. When native turtles were encountered on land, surveyors were instructed to keep $10 \mathrm{~m}$ away from animals in order not to disturb them and note the turtle's behavior. If a non-native turtle was discovered, the animal was removed from the wild and transferred to the Oregon Department of Fish and Wildlife (ODFW). A conservative count for the total number of depredated nests seen at each site in our analysis including GPS coordinates for only nests we were certain were not duplicates.

Surveyors recorded:

- start/end time

- precipitation within the last 48 hours

- number of people seen during the survey in the nesting area

- number and state of dogs seen (leashed, off-leash, in the water)

- notes of other activity or wildlife pertinent to turtle nesting (i.e., bullfrogs)

GPS points of nesting activity:

- Intact nest: Undisturbed turtle nest with eggs deposited and buried

- Depredated nest: Turtle nest with eggs deposited, then excavated by a predator and destroyed/consumed often with curled up eggshells present

- Aborted nest attempt: Turtle nest begun to be dug, then aborted before eggs were deposited due to impenetrable substrate or the approach of a potential threat

- Turtle on land: Turtle sighted on land, most likely a female attempting to nest

The number of people and dogs observed were recorded to identify potential anthropogenic impacts on turtle nesting activity. Data on the rate of people present in nesting areas was supplemented by TRAFx pedestrian trail counter data from the Metro Regional Government ${ }^{1}$. Precipitation within the past 48 hours was recorded by surveyors to calibrate detection probability of intact nests. Survey sites with greater nesting activity received more site visits, as did sites close to urban centers as volunteers were encouraged to visit sites close to their homes. All 25 sites visited in 2019 were revisited at least twice during the 2020 nesting season.

\section{Emergence Surveys}

All intact nests found during the nesting surveys that were not yet depredated were "caged" with a $30 \times 30 \mathrm{~cm}$ square of $1.9 \mathrm{~cm}(3 / 4 ")$ mesh hardware cloth pegged in place with $7.62 \mathrm{~cm}$ nails to prevent depredation. Cages of intact nests were removed in the autumn of 2019 to allow for hatchling emergence and monitored monthly for signs of emergence. All intact nests were visited monthly from October through January and biweekly until they were excavated in mid-May 2020 to assess the ultimate fate of the eggs within the nests. Evidence from the nest and within

\footnotetext{
${ }^{1}$ TRAFx pedestrian counters use infrared to record hourly trail usage and have been used by Metro to improve regional pedestrian trails throughout the Portland Metro area for over a decade.
} 
the nest chamber was categorized by the likely outcome. (Table 1). Vertical holes emerging from intact nest locations were considered successful hatchling emergence.

\begin{tabular}{|l|c|}
\hline \multicolumn{1}{|c|}{ Evidence } & Interpretation \\
\hline$\sim 3 \mathrm{~cm}$ hole with vertical orientation & Successfully emerged hatchlings \\
\hline $\begin{array}{l}\text { Eggshell fragments in nest } \\
\text { chamber }\end{array}$ & Successfully emerged hatchlings \\
\hline Unhatched eggs/Dead hatchling & In-nest mortality \\
\hline Absence of eggshells & $\begin{array}{l}\text { The nest may have been incorrectly identified and no } \\
\text { eggs were laid, OR there were successfully emerged } \\
\text { hatchlings and the eggshells could not be located. }\end{array}$ \\
\hline
\end{tabular}

Table 1: Interpretation of evidence from 'intact' nests

\section{Substrate Sampling}

Methods for substrate sampling were adapted from the USDA Soil Survey Field and Laboratory Methods Manual (2014). Multiple 500g soil samples were collected from both random and nonrandom locations within likely turtle nesting areas at eight of the sites, in the Columbia Slough (n $=6)$ and the Tualatin Basin $(n=2)$. The sampling was biased towards the Columbia Slough Basin which has a long history of land management actions including deposition of dredge spoils. Substrate samples were taken at a depth of up to $15 \mathrm{~cm}$, the maximum depth of native turtle nests in Oregon, from both known nest sites and sites without documented nesting activity. Each bag was mixed well to homogenize the soil sample before performing the graduated cylinder test.

The graduated cylinder test for texture was used to reveal the dominant soil type (sand, silt, clay, or organic matter). $50 \mathrm{~mL}$ of sampled soil was measured into a $100 \mathrm{~mL}$ graduated cylinder. Water was then added to the $100 \mathrm{~mL}$ line, allowed to settle, and topped off until the water level rested evenly at $100 \mathrm{~mL}$. The top of the cylinder was covered with parafilm and slowly inverted repeatedly for 5 minutes to allow the soil to mix evenly with the water. The samples were allowed to rest for at least 24 hours and the contents measured according to substrate type: coarse was sand, more fine was silt, dissolved in water was clay (USDA, 2014).

\section{Population Estimates}

Data from visual observation surveys were used to estimate the turtle population size at 23 sites. The maximum number of native turtles observed during one survey was used as the minimum 
population size at the site. This is almost certainly an underestimate at all sites without markrecapture data.

Two sites had multi-year mark-recapture data available. The Lincoln-Petersen method was used to estimate population sizes using the formula:

$$
\mathbf{N}=(\mathbf{M} * \mathbf{C}) / \mathbf{R}
$$

Where $\mathrm{N}=$ estimated turtle population

$\mathrm{M}=\#$ marked turtles (Event 1)

$\mathrm{C}=$ \# captured turtles (Event 2 )

$\mathrm{R}=\#$ Recaptured turtles (Event 2)

The assumptions using this model are:

1. The system is closed, meaning that no individuals die, are born, move into or move out of the system;

2. No marks fall off of the animals between visits;

3. The researcher correctly records all marks.

With more mark-recapture data more accurate statistical methods of estimation exist, but for the existing data, the crude level of the Lincoln-Peterson method was sufficient and more accurate than the minimum turtle population estimate.

\section{Analysis}

ODFW historic records of turtle observations and data from statewide turtle nesting records was used to inform the analysis. Data were analyzed using Microsoft Excel and R. Distance and area were calculated using ArcMap 10.6 and ArcPro.

The test assumptions of normality and homoscedasticity were approximated once the data were transformed with ln transformations. In order to determine the effects of turtle population size and search effort on number of nests detected, we ran a multiple regression. An ANOVA was used to determine the effect of number of people passing by per hour on turtle nesting. Although the number of people was continuous, the relationship with the number of nests was non-linear and so the number of people was divided into two categories following a clear divide between $<5$ ( $\mathrm{n}=17$ sites $)$ and $>10(\mathrm{n}=7$ sites $)$ people per hour based on visual assessment of the relationship (Figure 8). 


\section{Results}

\section{Nest Survey Summary \& Findings}

185 surveys across 25 sites around the Portland Metro area during the 2019 turtle nesting season yielded 386 unique points of turtle nesting activity. Depredated nests accounted for $93 \%$ (262/280) of the identified nests where eggs were deposited (Figure 5A). Most nests categorized as depredated showed definitive signs of being eaten, such as curled up eggshells and signs of fresh digging (Figure 5B). Occasionally, there was no sign of eggshells and we were still able to categorize the nests as depredated by the style of excavation, likely by a canine (Fig 5C). Aborted nest attempts accounted for $27 \%$ of the observed nesting activity (Figure 5D). A majority of these, $66 \%$ (70/106), were recorded at three sites atop former or current packed gravel roadbeds. All turtle nesting locations in this study had high levels of solar exposure with no to minimal canopy cover. Vegetative cover ranged from $10-60 \%$ at sites of known nesting.

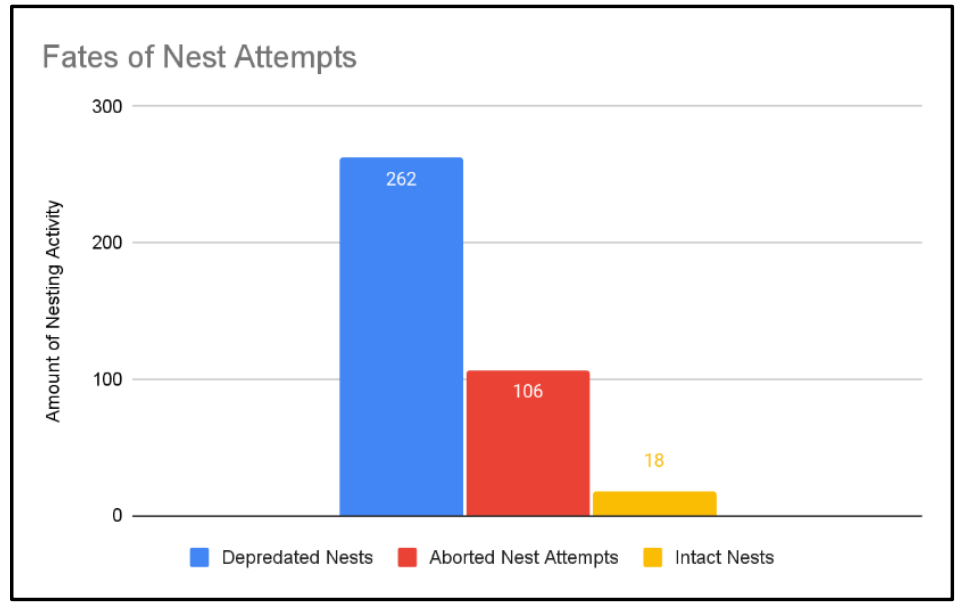

A.
B.

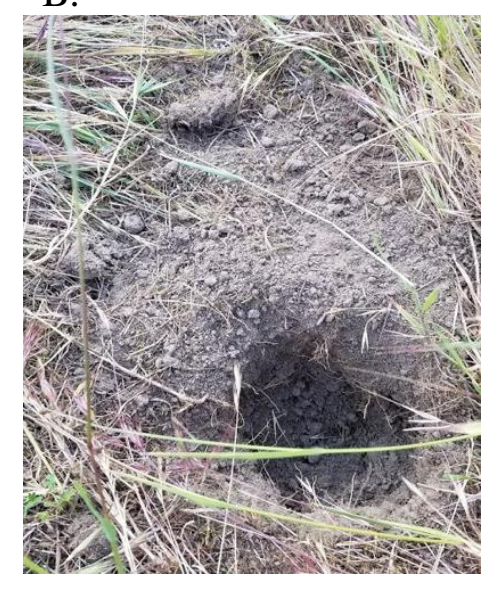


C.

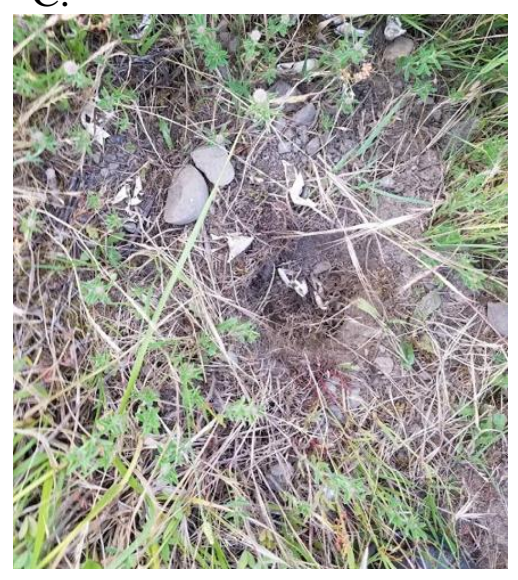

D.

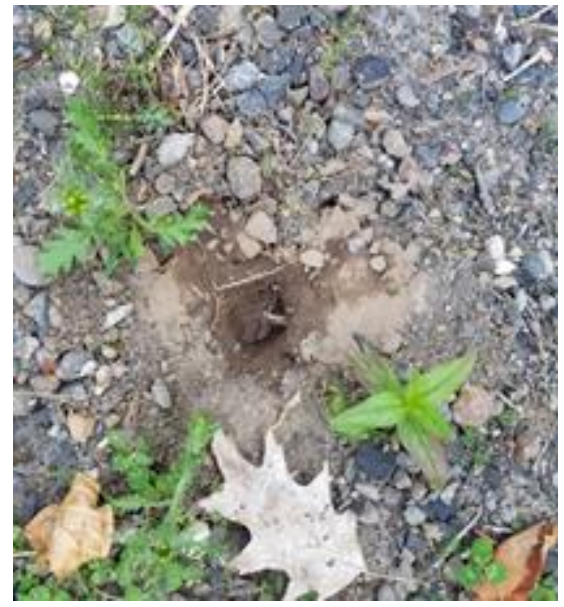

Figure 5: A large majority of nesting attempts were not successful. A. Bar chart of the summary of the 2019 Turtle Nesting Survey Results from all 25 sites. B. Photo of depredated nest. C. Photo of depredated nest without eggshells D. Photo of aborted nest attempt. Photos by J. Holley.

\begin{tabular}{|c|c|c|c|c|c|c|}
\hline Site Shield Code & Management Type & \# Surveys & Total Survey Time & \# Nests Attempts & Avg People/Hr & Min. Turtle Pop. \\
\hline A & industrial & 9 & 1806 & 65 & 0 & 170 \\
\hline $\mathrm{B}$ & $\operatorname{Rec}$ & 11 & 485 & 0 & 20 & 2 \\
\hline $\mathrm{C}$ & $\operatorname{Rec}$ & 8 & 386 & 0 & 14 & 2 \\
\hline D & Nat. Area & 2 & 130 & 0 & 2 & 0 \\
\hline$E$ & $\operatorname{Rec}$ & 8 & 260 & 0 & 38 & 2 \\
\hline $\mathrm{F}$ & Both & 6 & 865 & 5 & 4.33 & 15 \\
\hline G & Nat. Area & 6 & 600 & 37 & 0.5 & 16 \\
\hline $\mathrm{H}$ & Nat. Area & 10 & 955 & 14 & 0.97 & 125 \\
\hline 1 & private & 5 & 380 & 0 & 0 & 30 \\
\hline J & $\operatorname{Rec}$ & 5 & 390 & 0 & 10.12 & 10 \\
\hline $\mathrm{K}$ & Nat. Area & 15 & 1290 & 2 & 0 & 10 \\
\hline $\mathrm{L}$ & private & 3 & 350 & 2 & 0 & 5 \\
\hline M & Nat. Area & 6 & 975 & 42 & 1.5 & 100 \\
\hline $\mathrm{N}$ & Nat. Area & 9 & 645 & 14 & 0 & 12 \\
\hline 0 & Nat. Area & 6 & 720 & 5 & 0 & 15 \\
\hline $\mathrm{P}$ & Nat. Area & 7 & 1320 & 35 & 1 & 30 \\
\hline$Q$ & Nat. Area & 5 & 435 & 19 & 0 & 4 \\
\hline $\mathrm{R}$ & private & 6 & 265 & 0 & 0 & 13 \\
\hline$S$ & Nat. Area & 15 & 1805 & 64 & 1.65 & 200 \\
\hline $\mathrm{T}$ & Nat. Area & 6 & 1050 & 1 & 0.138 & 4 \\
\hline U & Both & 8 & 160 & 0 & 30 & 2 \\
\hline V & industrial & 7 & 1795 & 6 & 0 & 2 \\
\hline W & $\operatorname{Rec}$ & 12 & 816 & 1 & 21.7 & 2 \\
\hline$x$ & Nat. Area & 6 & 693 & 1 & 0 & 17 \\
\hline Y & Both & 6 & 440 & 2 & 13.6 & 50 \\
\hline
\end{tabular}

Table 3: Site data used for primary analyses. Site names have been shielded for the protection of turtle populations. 
Depredated nests were generally found in clusters in predicted areas of high solar exposure and sparse vegetation. The densest cluster contained 31 depredated nests in an area less than three square meters. The most distant points $(>100 \mathrm{~m}$ from water) were generally scattered single nest sites, but more than $80 \%$ were within $40 \mathrm{~m}$ from water and classified as clustered. Approximately $75 \%$ of the primary survey areas were within $40 \mathrm{~m}$ of water.

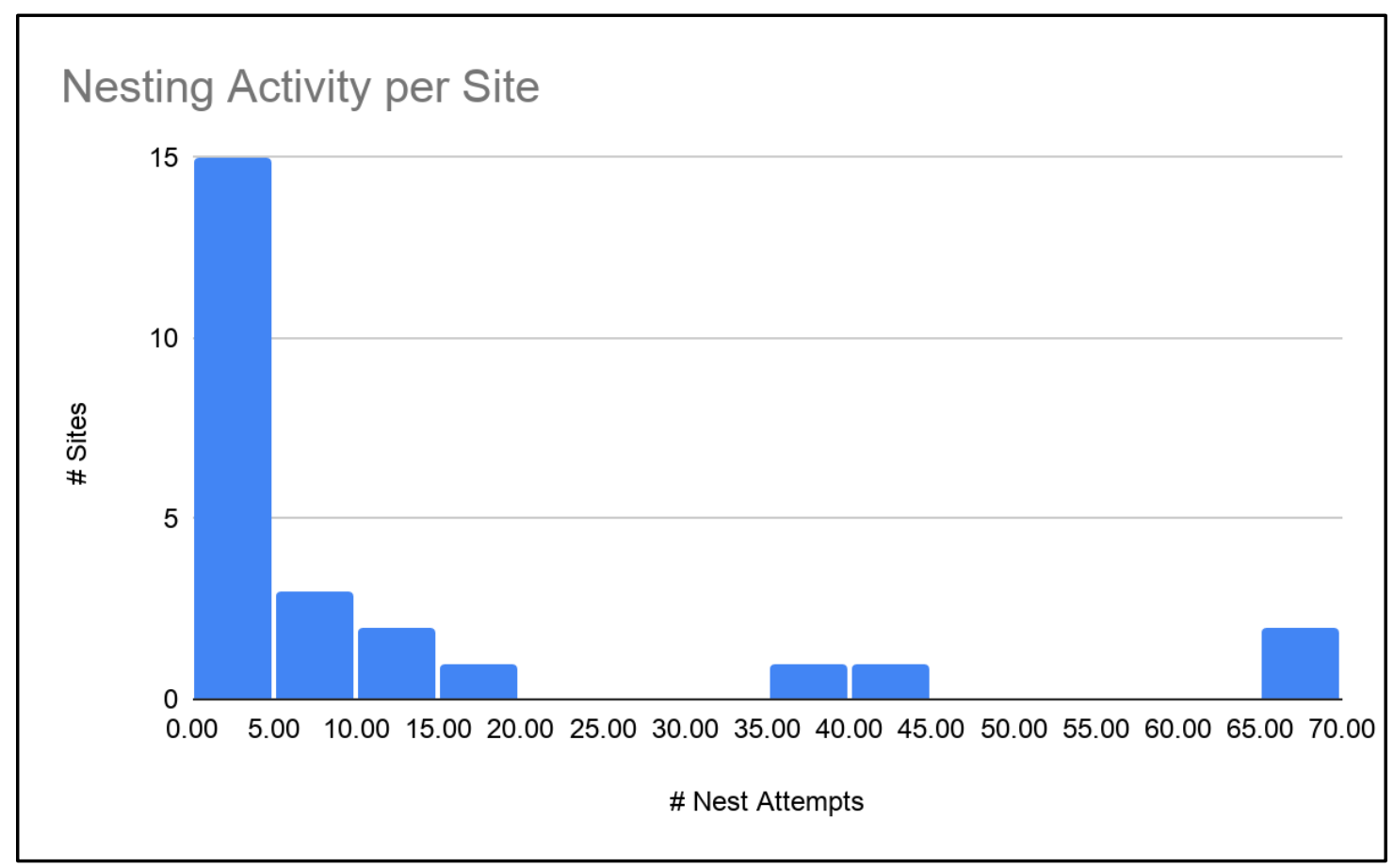

Figure 6: Histogram of the distribution of nesting activity by site across the 25 turtle sites in the greater Portland metropolitan area. 


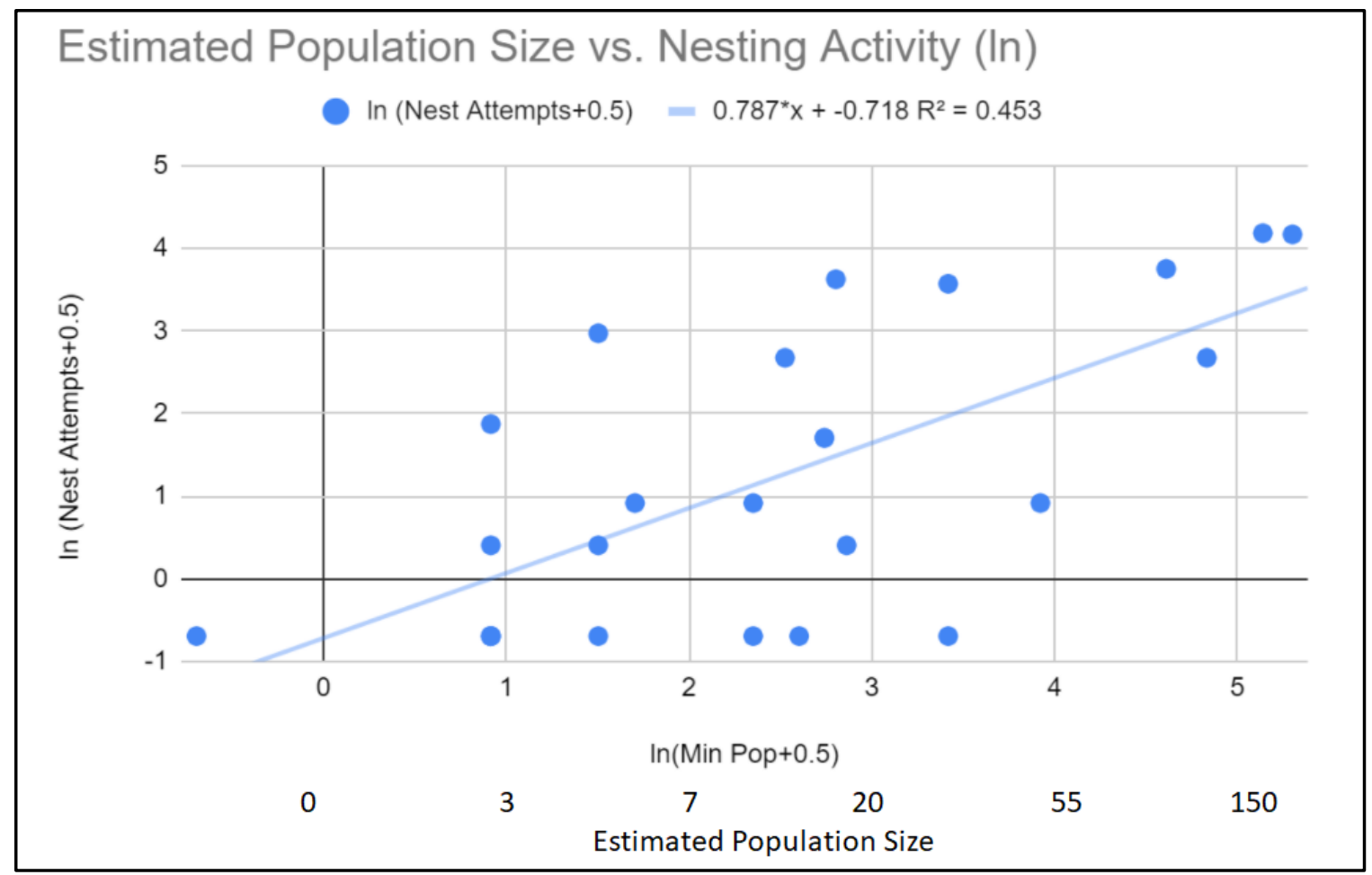

Figure 7: A. Scatterplot of nesting activity versus estimated minimum population size of painted and pond turtles across 25 sites in the greater Portland metropolitan area. The trendline of the natural log transformation demonstrates that nesting activity increased with increasing population size. Regression was performed on transformed data giving an $\mathrm{R}^{2}$ value of 0.45 , the formula for the trendline is Nesting $=0.787 \mathrm{x}-0.718$. Nontransformed numbers are given below the values of log transformed numbers. 


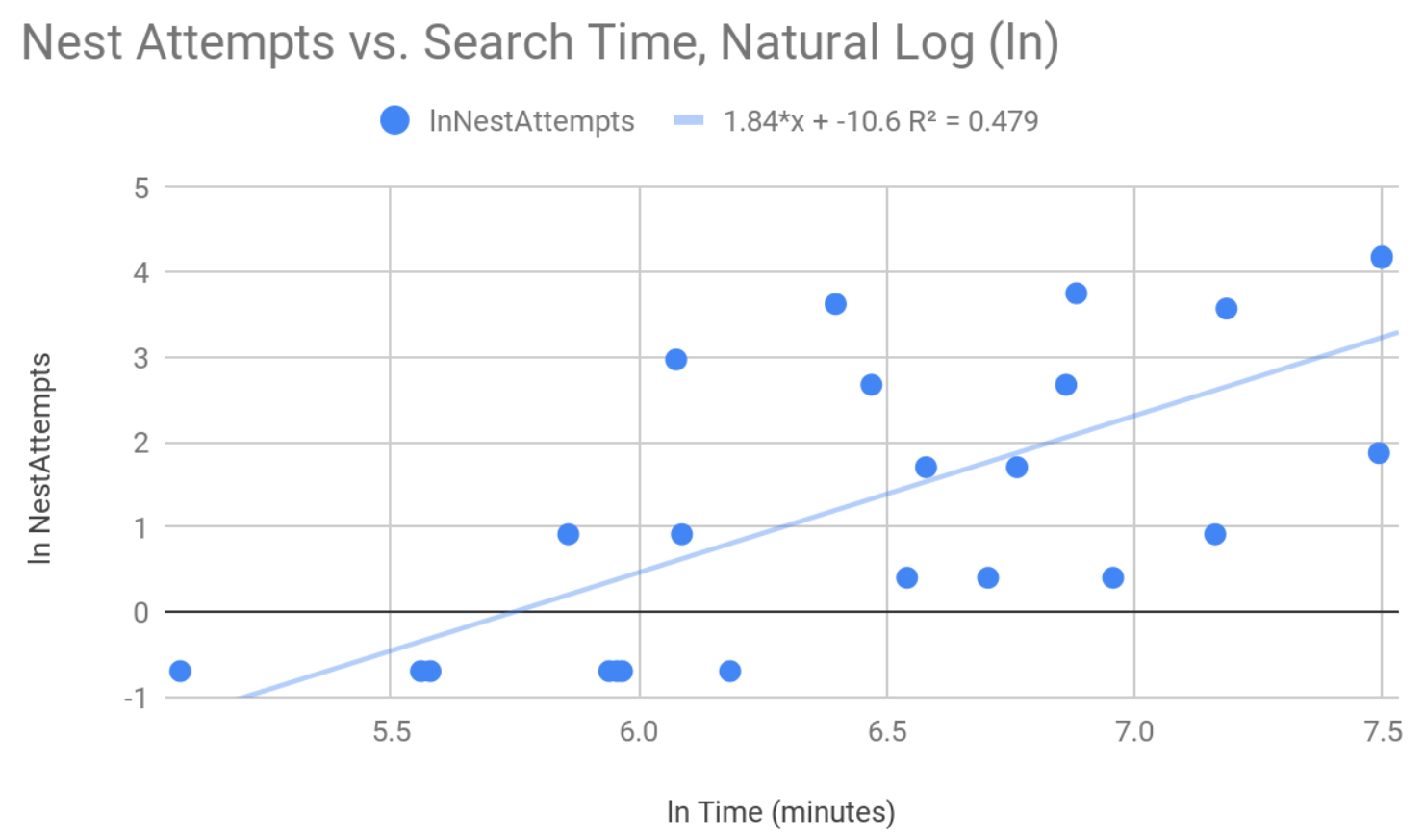

Figure 8: Scatterplot of natural log transformation of search effort versus nesting activity. The trendline of the natural $\log$ transformation is $1.84 \mathrm{x}-10.6$ with an $\mathrm{R}^{2}$ value of 0.48 .

\section{Human Impact on Nesting Rates}

2019 Turtle Nesting Activity $=23.7+-6.33 \ln \times R^{2}=0.306$

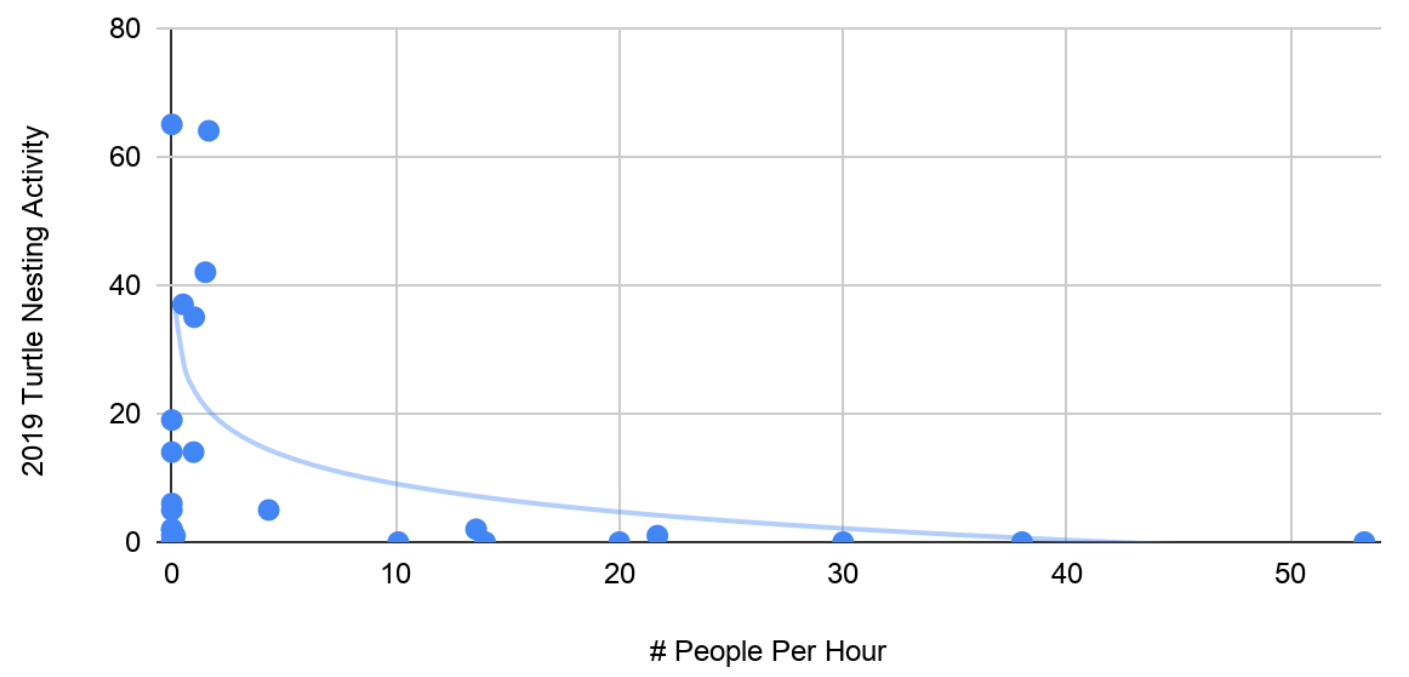

Figure 9: Scatterplot of the number of people seen at turtle nesting areas per hour (averaged) against the number of nest attempts seen at the site. The logarithmic trendline best fits the shape. A table of the data used for this analysis is included in Appendix A. 


\begin{tabular}{|c|c|c|c|c|c|c|}
\hline $\begin{array}{c}\text { Nest } \\
\quad \#\end{array}$ & $\begin{array}{c}\text { Date of } \\
\text { signs of } \\
\text { emergence }\end{array}$ & Basin & \# Eggs & Species & Observations & Fate \\
\hline 1 & $\begin{array}{l}\text { August 30, } \\
2019\end{array}$ & Tualatin & 11 & ACMA & $\begin{array}{l}\text { Restoration activity } \\
\text { placed nest in } \\
\text { potential harm's way }\end{array}$ & $\begin{array}{c}\text { Nest excavated by } \\
\text { ODFW August } 2019 . \\
2 \text { undeveloped eggs } \\
\& 9 \text { hatchlings raised } \\
\text { in captivity }\end{array}$ \\
\hline 2 & $\begin{array}{l}\text { February } 20, \\
2020\end{array}$ & $\begin{array}{l}\text { Columbia } \\
\text { Slough }\end{array}$ & UNK & UNK & Vertical Hole & No eggshells in May \\
\hline 3 & March 7, 2020 & $\begin{array}{l}\text { Columbia } \\
\text { Slough }\end{array}$ & $\sim 7$ & CHPI & $\begin{array}{c}\text { Vertical Hole, } \\
\text { hatchlings already } \\
\text { emerged }\end{array}$ & $\begin{array}{c}\text { About } 7 \text { eggshells in } \\
\text { May }\end{array}$ \\
\hline 4 & $\begin{array}{l}\text { March 20, } \\
\quad 2020\end{array}$ & $\begin{array}{l}\text { Columbia } \\
\text { Slough }\end{array}$ & Minimum 5 & CHPI & $\begin{array}{l}\text { Hatchlings emerging } \\
\text { through vertical } \\
\text { hole. }\end{array}$ & $\begin{array}{c}\text { Eggshells of 5-8 eggs } \\
\text { in May }\end{array}$ \\
\hline 5 & April 12, 2020 & $\begin{array}{l}\text { Columbia } \\
\text { Slough }\end{array}$ & $\sim 8$ & CHPI & $\begin{array}{l}\text { Vertical hole of } \\
\text { emergence }\end{array}$ & $\begin{array}{l}\text { Eggshells fragments } \\
\text { in May }\end{array}$ \\
\hline 6 & April 14, 2020 & $\begin{array}{l}\text { Columbia } \\
\text { Slough }\end{array}$ & Minimum 5 & CHPI & $\begin{array}{l}\text { At least } 5 \text { hatchlings } \\
\text { emerged through } \\
\text { vertical hole }\end{array}$ & $\begin{array}{l}\text { Eggshell fragments } \\
\text { in May }\end{array}$ \\
\hline 7 & April 14, 2020 & Tualatin & 10 & CHPI & $\begin{array}{c}\text { Nest emerged into an } \\
\text { exclosure. No sign of } \\
\text { definitive emergence } \\
\text { hole }\end{array}$ & $\begin{array}{l}\text { No sign of any } \\
\text { eggshells after } \\
\text { excavation }\end{array}$ \\
\hline 8 & April 15, 2020 & $\begin{array}{l}\text { Columbia } \\
\text { Slough }\end{array}$ & $6-12$ & UNK & $\begin{array}{l}\text { Vertical hole of } \\
\text { emergence }\end{array}$ & $\sim 8$ eggshells in May \\
\hline 9 & May 13,2020 & Tualatin & 20 & TRSC & 20 undeveloped eggs & $\begin{array}{l}\text { All eggs failed to } \\
\text { develop, likely due } \\
\text { to poor substrate }\end{array}$ \\
\hline $10-17$ & $\begin{array}{l}\text { May 11-18, } \\
2020 \\
\text { Excavations }\end{array}$ & All & 0 & None & $\begin{array}{c}8 \text { nests excavated. } \\
\text { All } 8 \text { with no signs } \\
\text { of emergence or } \\
\text { eggshells }\end{array}$ & $\begin{array}{l}\text { Emerged without a } \\
\text { trace (possible) or } \\
\text { misidentified nest }\end{array}$ \\
\hline 18 & May 14,2020 & $\begin{array}{l}\text { Columbia } \\
\text { Slough }\end{array}$ & 7 & CHPI & $\begin{array}{l}\text { Previously } \\
\text { undetected nest with } \\
\text { hatchlings emerging }\end{array}$ & $\begin{array}{l}7 \text { hatchlings } \\
\text { emerging from } \\
\text { vertical hole }\end{array}$ \\
\hline
\end{tabular}

Table 4: Fate of caged intact nests. ACMA = Actinemys marmorata, $\mathrm{CHPI}=$ Chrysemys picta bellii, $\mathrm{TRSC}=$ Trachemys scripta elegans.

Nesting activity was not evenly distributed across sites (Figure 6). Three main measured factors affected the observed amount of detected nesting activity. Two of the factors strongly influenced the amount of nesting detected and should be included as covariates in nesting models: the turtle estimated population size and search effort by observers (Figures $7 \& 8$; Multiple regression: $\mathrm{R}^{2}$ 
$=0.61, \mathrm{~F}_{2,21}=16.34, \mathrm{n}=24, \mathrm{p}<0.001$; survey time $\mathrm{t}=3.21, \mathrm{P}=0.004$, population size $\mathrm{t}=2.64$, $\mathrm{p}=0.015$ ). The amount of nesting activity observed at a given site increased with an increase in the estimated size of the turtle population at the site. Similarly, the amount of nesting activity detected increased proportionally to the hours of search effort at most sites. However, less nesting activity was found for a given search effort at sites in the Tualatin Basin and on the Willamette River suggesting that the lack of detection there was not due to lack of effort, but an actual lack of nesting activity at the sites (Figure 9).

The amount of nesting at a site was also correlated with the number of pedestrians observed at turtle nesting sites. Figure 9 is a scatterplot of nesting sites with the number of people seen per hour near nesting areas on the $\mathrm{x}$-axis and the amount of nesting activity on the $y$-axis (ANOVA $\left.\mathrm{F}_{1,22}=13.17, \mathrm{P}=0.001\right)$. Sites with greater than 5 humans sighted per hour showed an extreme drop-off in observed nesting activity. Most sites (15) had fewer than 5 detected nest attempts, including 8 sites with no observed nesting activity. Four of the eight sites without nesting activity were in urban areas with low turtle population estimates ( $<5$ native turtles) and high levels of human recreational activity (greater than 5 people per hour). Another 3 sites with no recorded nesting activity were along the Willamette River in more rural settings. These sites have larger estimated population sizes but also have a much wider range of nesting habitat available to them, making nest location identification more challenging than at relatively confined urban sites. Two sites had over 65 known nesting attempts and have native turtle populations greater than 100 turtles estimated in the site population (Figure 8A).

Ten encounters with native turtles on land were recorded; all were observed in the evening between 1800 and 2300. Eight gravid female T. scripta elegans were discovered during the surveys attempting to nest. All were removed from the wild and delivered to ODFW personnel. All observed T. scripta elegans nesting activity occurred between 0930 and 1300.

Five intact nests were discovered by surveyors other than the lead researcher during the 2019 survey season. Since these nests were discovered by volunteers without the proper authority to handle wild animals, they were not all caged within 48 hours and all were depredated within one week. None of the 17 observed intact nests showed external signs of disturbance after being caged to protect them from predators.

\section{Emergence Times}

All 17 caged intact nests were monitored monthly for signs of emergence from October 2019 through May 2020. All intact nests were carefully excavated by hand in May regardless of the evidence of hatchling emergence. None of the nests we monitored showed any sign of natural emergence until February (Table 4). The first two signs of emergence discovered (2/28 \& 3/10) were vertical holes emerging from the nests site and could have occurred anytime over the previous 2 weeks. One previously undiscovered nest was found in May 2020 with C. picta bellii 
hatchlings emerging, increasing the total to 18 intact nests. Two nests had known spring hatchling emergence with no sign of eggshells when excavated in May. Eight nests showed no sign of emergence or eggshells upon excavation in May and were either misidentified as nests, were depredated underground, or emerged without obvious evidence.

The nests averaged 36m from water (Table 5). The farthest discovered nest laid was $174 \mathrm{~m}$ from the water's edge at a site on the Clackamas River with only C. picta bellii known to be present at the site. A nest in the Tualatin Basin known by observation to be laid by a female A. marmorata was $158 \mathrm{~m}$ from shore. The furthest distance a nest was recorded from the water's edge at an urban site was $54 \mathrm{~m}$. The minimum distance from shore was $1 \mathrm{~m}$, with the nest located below the mean annual flood levels. Unexpectedly, average distances varied little between urban and rural sites (Table 5). The urban Columbia Slough and Tualatin Basin nests averaged $37.1 \mathrm{~m}$ and $30.6 \mathrm{~m}$, respectively. Zero nesting activity was detected along the Willamette mainstem (Figure 10).

Most nests at both urban and rural sites were identified within $20 \mathrm{~m}$ from the shore of ponds.

A cluster of 4 nests at 4 different sites emerged within 4 days of one another in mid-April. No clear pattern in emergence time was visible as a function of precipitation or temperature events with the small sample size (Figures 11B \& 11C). All observed emerged hatchlings were $C$. picta bellii. 


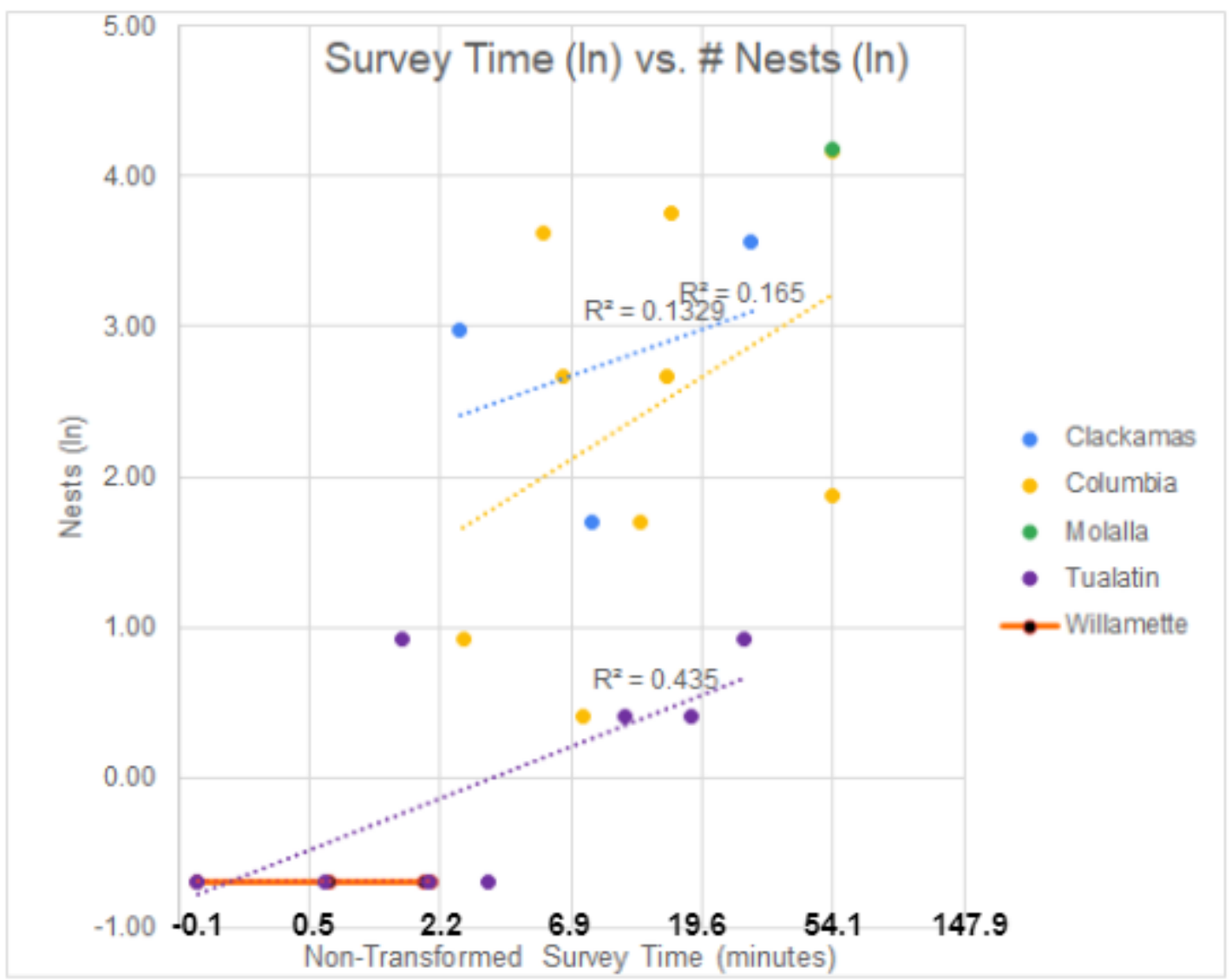

Figure 10: A scatterplot of natural log transformed data of search effort versus nesting activity by basin.

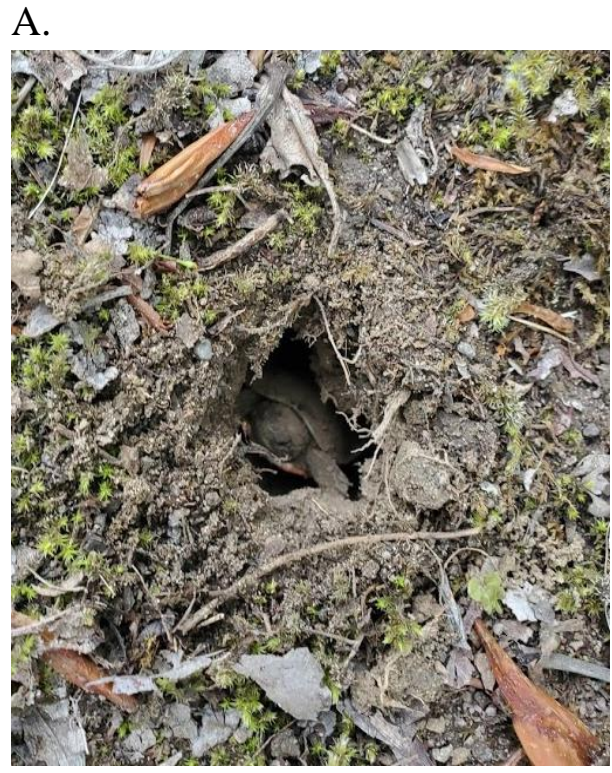

B. 


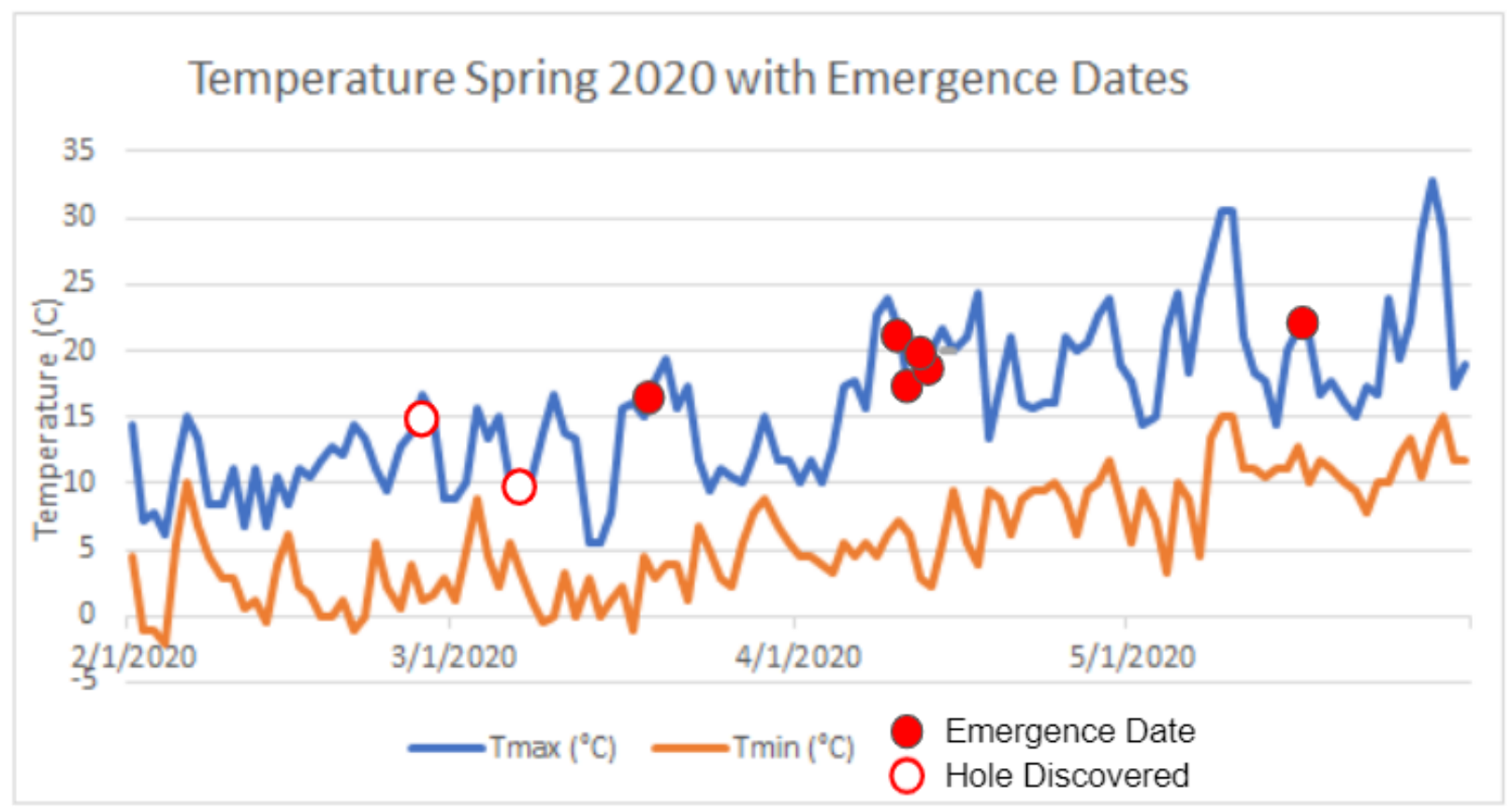

C.

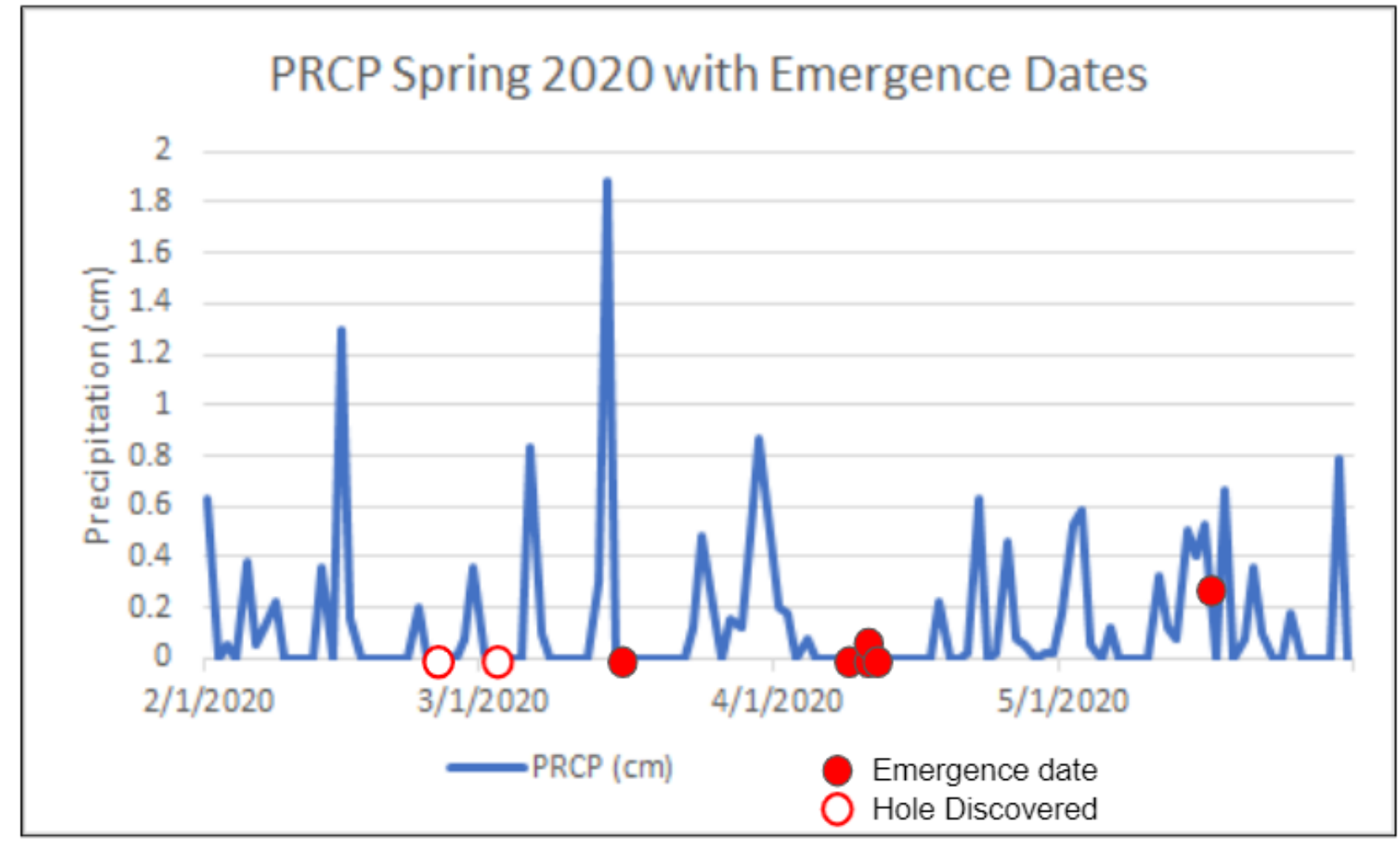

Figure 11: A. Image of hatchling C. picta bellii emerging. B. Emergence dates (red circles) plotted along with temperature and C. Precipitation data from NOAA data spring 2020 at the Portland airport. Open circles indicate a hole likely created by an emerging hatchling was found, but exact emergence date is unknown. 


\begin{tabular}{|l|l|l|}
\hline & Urban Sites & Rural Sites \\
\hline MAX Distance & $54 \mathrm{~m}$ & $174 \mathrm{~m}$ \\
\hline Min Distance & $1 \mathrm{~m}$ & $3 \mathrm{~m}$ \\
\hline Mean Distance & $36.5 \mathrm{~m}$ & $36.1 \mathrm{~m}$ \\
\hline Standard Deviation & 22.1 & 24.2 \\
\hline
\end{tabular}

Table 5: Distance from water's edge to nest location. Distance was measured from water levels at the end of July 2019.

\section{Flight Initiation Distance (FID)}

FID was not studied specifically in the field during this study. Based on observations of turtle behavior at typical basking locations and the GIS-determined straight-line distance between those points and the nearest established paths, I determined $40 \mathrm{~m}$ to be the threshold path distance beyond which turtles are less likely to disrupt their behavior $(n=12)$. One site with high levels of pedestrian traffic less than $40 \mathrm{~m}$ from a turtle basking site has a $3 \mathrm{~m}$ buffer of riparian shrubs and trees obscuring line of sight. Here, turtles have not been observed to continue their basking activity rather than bailing into the safety of the water as observed at all other sites in this study with human activity within this distance lacking a substantial riparian buffer. This implies that this vegetative barrier is sufficient to insulate the wildlife from feeling threatened at this location.

\section{Substrate}

Substrate was sampled at four sites in the Columbia Slough Basin and two sites in the Tualatin River Basin with substantial nesting activity. Results of the graduated cylinder test for texture showed a fairly narrow range of substrate composition across the sites (Table 6). Sand was dominant at almost all sites with a mean value of 59\%. Clay presence was minimal with no samples containing greater than $14 \%$ clay.

\begin{tabular}{|c|c|c|c|}
\hline & $\%$ Sand & $\%$ Silt & \% Clay \\
\hline mean & 59.55 & 34.28 & 2.94 \\
\hline Median & 62.11 & 34.78 & 2.17 \\
\hline Maximum & 97.78 & 71.65 & 13.19 \\
\hline Minimum & 21.76 & 2.22 & 0.000 \\
\hline Std Dev & 21.08 & 20.26 & 2.66 \\
\hline
\end{tabular}

Table 6: Summary statistics of substrate samples within nesting habitat at a subset of sites 


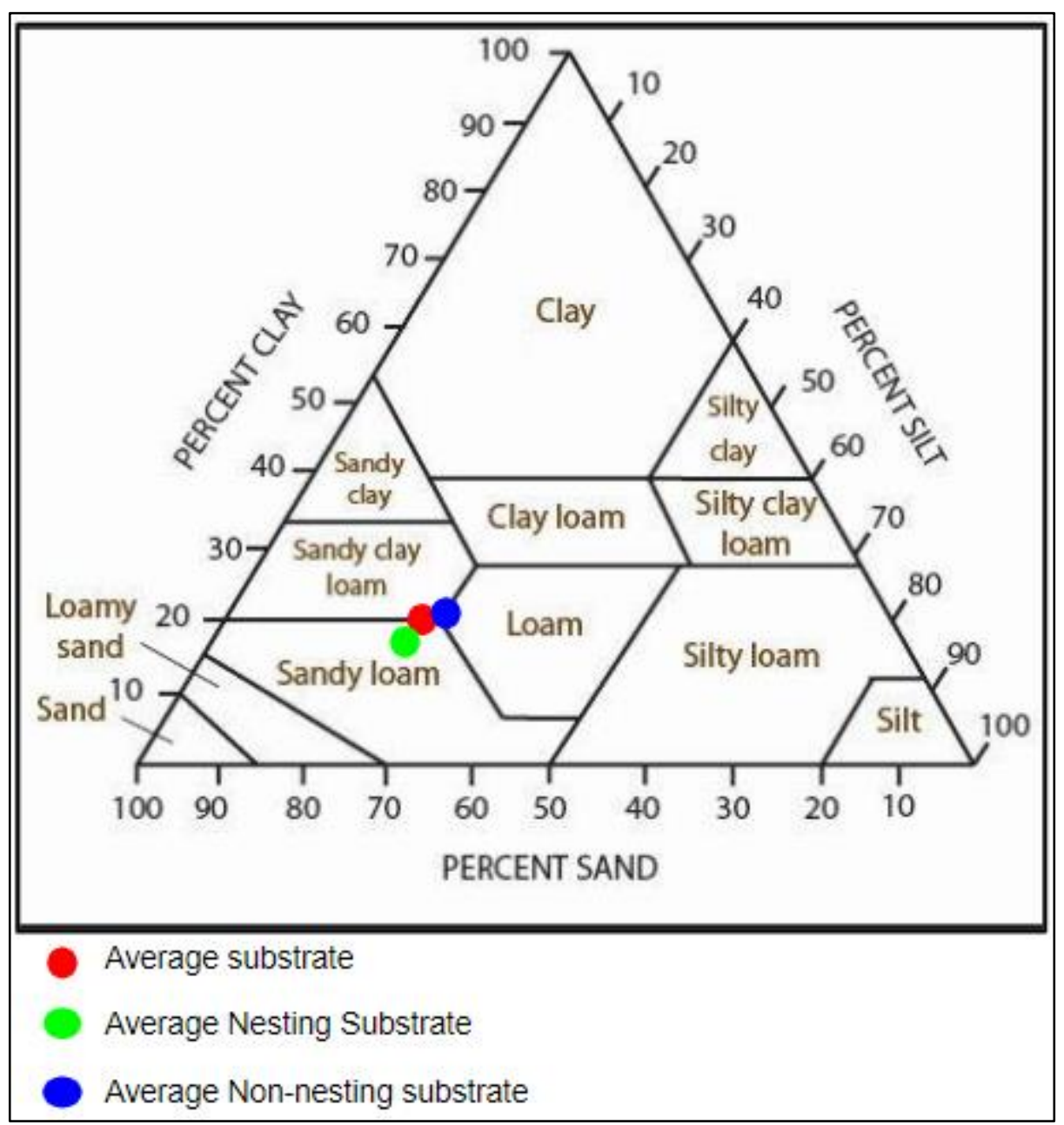

Figure 11: Sediment triangle with average substrate represented by the red circle.

\section{Discussion}

\section{Nest Surveys}

While some turtle nesting studies have been conducted in the Pacific Northwest, extensive, coordinated turtle nesting surveys had not previously been performed in the Lower Willamette region prior to this study (Delaney et al., 2017). Anecdotal evidence and findings of nesting studies from other parts of the painted turtle's extensive range have been generally assumed to hold true in the Pacific Northwest, however, the genotypes of this subspecies could easily differ from those east of the Rocky Mountains. This study used field-collected data to evaluate the basic nesting requirements of Portland-area turtle populations and then integrated the findings with the literature to develop suggestions for habitat improvements and future studies. All 25 sites visited in 2019 were revisited at least twice during the 2020 nesting season, and similar 
nesting areas were identified in the second year, lending confidence to our understanding of known nesting habitat qualities and locations relative to aquatic habitat in the region.

\section{Depredation Rates}

The depredation rate of $93 \%$ recorded in this study is significantly higher than that found in most other studies on turtles and is a stark contrast to the $17.4 \%$ depredation rate found in a study on C. picta marginata in rural Michigan (Rowe et al., 2009). The low number of discovered intact nests could be caused by efficient hunting by large mesopredator populations, detection failure of subtle intact nests by surveyors, or a combination of both. We believe the $93 \%$ rate is actually lower than the actual rate due to confusion relating to GPS points during data collection, discussed below.

\section{Urban turtles}

Many of the sites in this study are urban in nature so viewing the situation through an urban ecology lens can help explain the high 93\% depredation rate. Urban areas, lacking wild apex predators, are known to have increased populations of mesopredators, the primary consumers of turtle nests (Ritchie et al., 2009). Urban areas are also characterized by confined spaces delineated by anthropogenic barriers (walls, fences, roads, etc.) limiting the amount of suitable nesting areas for turtles to nest, and, also, the area predators need to efficiently search for food resources. Efforts to better understand mesopredator populations in urban habitats are necessary to better understand urban turtle population dynamics.

\section{Nest distance from water}

An experiment on simulated painted turtle nests demonstrated that both nest distribution and proximity to ponds affect depredation rates (Marchand, et al., 2004). They found depredation rates were highest on clumped nests near ponds ( $<50 \mathrm{~m}$, depredation: $68 \%)$, followed by scattered nests near ponds (40\%), clumped nests far from ponds (100-150m; 34\%), and, finally, the lowest predation rates were on scattered nests far from ponds (26\%). These data support the microhabitat hypothesis that small patches of one or two nests are more likely to survive than large clusters of turtle nests (C. Yee, ODFW, pers. comm.). The nests in our study were found predominantly $<30 \mathrm{~m}$ from the water's edge and the majority were necessarily clumped in bunches $<3 \mathrm{~m}$ from another nest as the areas of suitable nesting habitat were highly limited at most sites.

The mean distances from water in this study are substantially less than findings from studies in other areas. A study in northern Michigan on C. picta marginata found the mean distance from water of nests was $173.5 \mathrm{~m}$ with a minimum distance of $31 \mathrm{~m}$ and a maximum distance of $381 \mathrm{~m}$ (Rowe et al, 2009). The mean distance from ordinary high water of ponds to nests found in this study was $36.5 \mathrm{~m}$ in urban settings and $36.1 \mathrm{~m}$ in rural settings with maximum distances of $54 \mathrm{~m}$ and $174 \mathrm{~m}$, respectively. The low average distance in urban areas is easily explained by the 
confined spaces inherent to urban places, but the low mean distance of rural sites is somewhat surprising. This can be at least partially explained by the large percentage of rural nesting activity found at two high activity sites in this study. One is an industrial area with nesting habitat limited primarily to the pond edges within the property boundaries. The nesting activity at the second rural site was concentrated at two nesting areas within $10 \mathrm{~m}$ of the water's edge where high levels of solar exposure and diggable substrate were ample.

Nesting is likely the most dangerous act of a female turtle's year. During the nesting process, turtles were less likely to flee from a predator when they were further from water or had already initiated nesting (Delaney et al. 2017), Hence, turtles may be weighing the cost already invested into the nesting foray versus the risk of predation and benefit of completing the nest. The risk faced by adult female turtles increases with nesting greater distances from water due to increased predation risk on them and, potentially, more road crossings which makes them vulnerable to being struck by cars (Steen et al., 2004). Although adult females nesting nearer to water can more easily seek the safety of the aquatic environment if threatened, there is a trade off with egg survival as predators have been found to key onto nests more easily if they are grouped along the water's edge (Marchand et al, 2004). Our study focused on nesting habitat near water $(<40 \mathrm{~m})$ due to the constraints of property boundaries, potentially explaining a part of the huge rates of depredated nests.

\section{Human Impacts on Turtle Nesting and Population Size}

We found that the amount of nesting activity versus the number of people seen per hour at the nesting area was negatively correlated. While it is known that human presence can disrupt turtles before they begin nesting, this is likely not the full story (Delaney et al, 2017; Holley pers. obs.). There are many unknowns regarding turtle nesting activity. The motivations and specific cues that a gravid female uses to time her nesting activity and select a site are still cryptic. The number of nests found, no matter how great the search effort, will almost always be an underestimate of true nesting activity. Sites with greater turtle population sizes will, typically, have more nesting activity occurring (Figure 7). The overall amount of pedestrian activity is probably less important to turtle nesting than the amount of passersby specifically during the evening nesting hours when direct interactions are more likely to occur. At some sites, seasonal trail closures may help alleviate some of this impact on turtle nesting. Further research is required to gather data on the full impacts of human pedestrian traffic in nesting areas so that mitigation measures can be taken. An experiment gathering detailed information on the timing, frequency, and reactions of human-turtle interactions through direct observation coupled with the placing of pedestrian counting devices near turtle nesting sites will gather data necessary to develop more informed conclusions about human impacts on turtle nesting activities.

There is also likely to be a connection between human presence and both native and non-native turtle population sizes. Humans are the original source of introduced non-native species which 
apply pressure on native turtles for limited resources, particularly in urban areas (Cadi et al., 2004). The pervasiveness of humans, particularly in urban areas, is nearly ubiquitous. Turtles are known to interrupt basking activities when a threat passes a certain distance threshold (Polich et al., 2016). Constant pressures on turtle populations with regular infractions within their flight initiation distance radii can have long-term energy costs (Moore et al., 2006). Over time, turtles may migrate to find more suitable conditions, experience decreased reproductive potential, or die (Polich et al., 2016). With a two-century trend of population decline, observed nesting activity will tend to decrease as there are fewer females among a diminishing population to attempt to nest. Several sites in this study showed that urban turtles do not react to human activity when it is at least 40m away or a sufficient visual barrier is present. Therefore, sites seeking long-term occupation by native turtles should ensure that there are areas with a minimum $40 \mathrm{~m}$ buffer or a dense ( $2 \mathrm{~m}$ deep) riparian hedge separating turtles from human activities. Areas designed for turtle occupation should also contain other habitat features crucial to their survival and wellbeing, namely basking features in areas of high solar exposure and aquatic vegetation.

\section{Buffer Distance}

The distance of recommended buffers to reduce disturbance differ by local population and method of disturbance. A 7m buffer was recommended by Pittsfield \& Burger (2017) after finding that turtles in canals in New Jersey react to disturbance within 3m. Heppard (2018) found that boat traffic volume impacted ringed sawback turtle (Graptemys oculifera) turtle basking activities on the Pearl River in Mississippi. This study in Oregon found 40m to be the standard flight initiation distance at urban sites. Local conditions and disturbance regimes should be taken into account when creating site management plans including the location of walking paths, pedestrian water access points, placement of installed basking structures (e.g., proximity to shoreline), and vegetation restoration designs to include areas managed specifically for turtle nesting habitat.

\section{Historic Site Occupancy Decline}

A three-year occupancy analysis was performed by Samara Group for ODFW to better assess the current distribution of $A$. marmorata in Oregon during 2018-2020. They found that less than half of 330 historic pond turtle sites surveyed have current occupancy (Samara Group, 2021). Many of the sites have been developed and altered for human purposes and some were aquatic areas influenced by American beaver (Castor canadensis) that have experienced natural wetland succession. Future studies can be performed analyzing the fate of the formerly turtle-occupied sites versus the currently occupied sites including factors such as pedestrian activity, turtle population size and demographics, the area of aquatic habitat beyond a turtle population's flight initiation distance, occurrence of confirmed nesting activity, and other landscape variables that will benefit management recommendations for long-term sustainable native turtle populations. 


\section{Emergence}

Hatchling emergence times in this study were consistent with findings from other studies of $C$. picta from a similar longitude and climatic conditions (Murphy et al., 2020). The life strategy of overwintering in the nest and emerging in the spring appears to be common across turtle species, with greater than $90 \%$ of hatchlings reported emerging in early spring in a range of species (Gibson et al., 1977). The specific triggers for fall versus spring emergence remain unknown, but it is thought that hatchlings are able to determine when preferable conditions occur above ground from within their underground nests; potentially through the temperatures, soil moistures, and/or humidity they experience in the nest (Gibbons et al., 1978).

Eight of the sixteen caged intact nests had no evidence of emergence or eggshells indicating successful hatching, depredation, or egg mortality. Garter snakes (Thanmophis sp.) have been observed entering fresh Chrysemys picta bellii nests moments after the female concludes her nesting activity and would likely leave no eggshell remains by swallowing the eggs whole $(\mathrm{N}$. Staihar, pers. obs.).

\section{Non-native Turtle Competition}

During the course of this study, we found and removed eight adult female T. scripta elegans from sites while attempting to nest. All of these were discovered at urban sites in the late morning/early afternoon. $T$. scripta elegans, red-eared sliders, are native to the southeastern United States and a popular pet turtle globally. The traits that make them good pets also allow them to survive in a wide range of habitats outside of their native range. Reproducing populations are now found in the wild across much of the globe (Lambert et al., 2019). While direct predation on native turtles is not an issue, they utilize similar food sources, basking sites, and nesting areas. Growing distinctly larger, these non-native turtles can dominate prime basking sites (Cady et al, 2004; Lambert et al, 2019). Beginning nesting earlier in the season, $T$. scripta elegans can also alert and draw extra attention from mesopredators to a potential food source. $T$. scripta elegans reach sexual maturity at a younger age than Oregon's native turtles and have clutches of up to 30 eggs, while native turtles lay only a maximum of 16 eggs, the population size of these non-native turtles has the potential to dominate the habitat within one generation (Cady et al, 2004; S. Barnes pers. comm.).

T. scripta elegans populations have become established throughout Oregon, in particular Western Oregon (S. Barnes pers. comm). Efforts to decrease non-native species often target adult females in the population. While T. scripta elegans has been documented nesting at all times of day, the most frequently observed late morning nesting time typical of $T$. scripta elegans offers a unique opportunity to easily capture and remove the most important portion of any population: adult females. Daily late morning searches through the slider nesting season from Mid-May through late July are an excellent and easy way to target established non-native turtle populations (Holley pers. obs.). 


\section{Patterns Seen Across Nesting Habitats}

\section{Solar exposure}

Turtle nesting habitat is primarily defined by solar exposure (Ernst, 1994). Turtle eggs require the warmth of the sun for the fertilized embryo to properly develop. All turtle nests discovered during these surveys were in direct light with no/minimal canopy cover directly overhead. Using ESRI's solar radiation tool with a digital surface model can help identify the levels of solar exposure at known turtle locations and help identify other likely or potential nesting locations.

\section{Vegetation}

The second important factor for turtle nesting habitat is vegetation. Although turtles are tenacious and capable of digging through thick vegetation, areas of sparse vegetation allow turtles to dig more easily and are more likely to be selected as nesting sites. In the Willamette Valley, native grasses and forbs tend to bunch together and leave gaps between them as opposed to many non-native grasses, namely Phalaris arundinacea (reed canary grass), that often form large areas of dense monoculture, particularly in and adjacent to wetland areas. Cases have been documented of dead and/or entrapped live hatchlings found in root masses as gravid adult females were able to excavate nests, but young turtles were unable to effectively emerge to the ground's surface through the root network that grew after the time of egg deposition (S. Barnes pers. comm.). Some turtle nesting areas are sprayed with herbicides every three years to maintain preferred vegetation densities appropriate for turtle nesting (L. Guderyahn, pers. com.). Vegetation densities at nesting sites in this study were consistent with a range of $10-60 \%$ cover at all discovered individual turtle nests.

\section{Substrate}

Thirdly, the substrate of nesting areas must be composed of a range of finer substrates which turtles can excavate for their nests.. The literature suggests that painted turtles native to the Eastern United States prefer to dig nests in loose, well-drained soils (Baldwin et al, 2004, Ernst, 1994). Large (>3cm) aggregate and unnaturally dense substrates are often unusable as turtle nesting habitat as evidenced by the concentration of aborted nest attempts atop old roadbeds (Mitchell et al., 2019). Turtles have been observed removing individual rocks up to $5 \mathrm{~cm}$ in excavating their nests but are often not able to excavate an entire nest in the density often seen in roadbeds (Holley pers. obs). Clusters of test digs indicate that density of rocks (gravel and larger) is likely an issue as documented by the three sites with $66 \%$ of recorded aborted nest attempts in this study. At these sites, the unnaturally dense substrate found in artifically compacted areas served to limit vegetative growth and allow sunlight into otherwise vegetated areas, luring gravid females to attempt to nest in an ultimately unsuitable location. Oregon turtles are tenacious diggers and able to nest in a range of substrates, but intentionally compacted areas often present insurmountable barriers to nesting. 
The sex of a turtle is determined by the temperature of the nest during the middle third of the incubation period (Bull et al, 1985; Packard et al., 1987). C. picta eggs incubated in loam have lower nest temperatures and produce a greater percentage of male offspring than ones incubated in sand or gravel (Mitchell et al., 2019). Given this impact of substrate on nest temperatures and the sex ratios produced, as well as the potential for aborted nesting attempts in compacted substrate seen in our study, efforts to improve the composition of nesting substrate that is suitable for population recruitment are critical at both urban and rural turtle sites that have been altered from historic conditions.

Sites in urban locations are limited in area by anthropogenic barriers (e.g., roads, jersey barriers, fences). In addition, they face high levels of disturbance to the physical environment and increased predatory threats to both adult turtles and their nests. Dense vegetation adjacent to aquatic habitat limits the amount of area that meets the levels of solar exposure required for turtle nesting. In rural areas, agricultural fields frequently occupy large swaths of land surrounding ponds used for irrigation. In both urban and rural areas the remaining areas of high solar exposure and low vegetation density are often farm field borders, grazed pastureland, edges of Oregon white oak savanna and roadbeds (S. Barnes pers. comm.). In locations where the substrate density has been increased for human purposes, vegetative growth is impeded allowing sunlight to reach the earth's surface, creating apparently suitable nesting habitat. However, substrate densities are often beyond the capabilities of a turtle to extract, resulting in aborted nest attempts.

Installing nesting mounds or areas of appropriate turtle nesting substrate adjacent to aquatic habitat could increase and improve the areas turtles have to nest. Water features at many sites have many different uses and space is often at a premium. Mounds can create habitat above the mean flood level while keeping the surface area small in space-limited areas in parks and commercial settings.

\section{Seclusion}

After the above factors have been satisfied, turtle nesting habitat appears to require some amount of seclusion. Regular disturbance by predators or perceived threats can disrupt nesting activities, causing gravid females to retreat back to the water before they attempt to nest. Sites with high recreational usage can diminish or, potentially, preclude all turtle nesting attempts as humans are viewed as threats by cautious turtles. This study found that there was a stark divide in nesting activity with rates of pedestrian traffic greater than five people per hour. A follow up study is planned for the 2021 nesting season to better delineate and corroborate this finding using automated pedestrian counters at turtle nesting locations. 


\section{Population Estimates}

The population size of turtles occupying a site was correlated with the amount of nesting activity observed at the site in this study. (Figure 7). Using the maximum number of turtles observed at a single event is potentially a large underestimate of the actual local turtle population and also depends on the definition of a 'site', which has been defined as a 500m gap between turtle populations for other research in the Lower Willamette Basin (Barela, 2014). Methods utilizing both mark-recapture data and visual observation surveys estimate that the number of turtles observed represent about $15 \%$ of the total population in a study on A. marmorata in lotic habitat (Galea, 2004). Population size estimates at the two sites with mark-recapture data in this study are more accurate than estimates based on VES data of known minimum population size (Table 6). Gathering increased demographic data by trapping, nesting surveys, and visual encounter surveys will help improve population and demographic estimates.

\section{Long-term Solutions}

Adult animals of long-lived species (i.e. turtles) are far more important than hatchlings and juveniles for maintaining population size. Studies on A. marmorata show similarly high mortality rates for eggs and juvenile turtles and high survival rates as adults (Vander Haegen et al., 2009). Smithers (2015) noted that $C$. picta bellii populations will decline with only a $20 \%$ reduction in the survival of large adults, but the hatchling survival rate could drop to as low as $4 \%$ before the population growth rate declines. Maintaining and improving conditions of adult turtle habitat will ensure a steady population size, however, due to the enormous historic population decline and current high nest mortality rates, efforts to improve nesting and juvenile survival rates are imperative to increase population sizes. Ensuring that nesting habitat is available without road crossings will minimize additional mortality risks to nesting females.

While population recruitment can be low and slow, there must be some level of replacement for adult mortality over time. Given the loss of native turtles in recent history, maintaining the current population levels is the minimum effort necessary to ensure a self-sustaining population. Increasing wetland habitat complexity with small woody debris structures and restoring native aquatics plant diversity will likely help improve juvenile survival rates and ensure healthy turtle populations into the future. Further information on juvenile turtles is available in Appendix B.

\section{Study Limitations}

Nests found in this study were often clustered closely so that the error inherent in most GPS coordinates is not accurate enough to identify each individual nest. As GPS points were recorded redundantly some confusion resulted and the minimum possible value was used for all uncertain data points in our analysis. Minimizing the number of total nests used for analysis in this study, coupled with the fact that only one uncaged nest is known to have hatched at any of the 25 sites, it is probable that the true percentage of depredated nests was even higher than the $93 \%$ reported. 
The possibility exists that more nests, located both off and on-site, may have hatched successfully, as evidenced by the previously undiscovered nest emerging within the prime search area in May 2020, but probably not enough to drastically decrease the high rate recorded in the areas of study.

Multiple studies have been performed documenting increased depredation rates on turtle nests across species when they are marked in any way (Oddie, 2015; Rollinson et al., 2007). Future survey efforts would benefit from marking the already depredated nests, as no further damage can be done. Marking already depredated nests will improve data accuracy on the number and location of depredated nests in areas of dense activity. Caution should still be taken not to add any cues at intact nests for potential predators, which are already quite adept at locating turtle nests.

Although surveyors were trained to look for all signs of turtle nesting, the most obvious signs are of depredated nests, often with characteristic rolled up eggshells outside the nest chamber on the ground's surface. There is a possibility that surveyors were drawn to these gross signs of nesting activity and may have missed more subtle intact nests, potentially biasing the results towards a higher rate of depredated nests than the actual value. While efforts were made to include all potential nesting habitats, property boundaries and limited time did not allow for $100 \%$ sampling.

A future study focused on a single site involving weekly surveys from the final week of May through the end of July (10 weeks) should capture the vast majority of turtle nesting activity sufficient to document the existence of turtles having multiple clutches and the range of places they select for nesting. Surveys 2-7 times per week during peak turtle nesting times (1600-0000 and the following morning) should be performed if full documentation is to be approached. Recording nest locations on a physical map in addition to digitally will add the ability to verify the data. Distance from water should be measured in the field during the nesting season for consistency as GIS layers vary by time of year and how the wetland was delineated. Data on aspect and slope of the nests is also potentially valuable information to record.

\section{Other Data Gaps}

Other data gaps on native turtles in Oregon include:

- Temperature / humidity within nest chambers and their effects on nest outcome/egg hatch success

- Influence of soil substrate on nest success

- Response of gravid turtles to nest habitat creation/enhancement

- The influence of vegetation/roots on hatchling emergence

- Determiners of hatchling emergence timing 
- Ability of turtle nests (eggs or hatchlings) to withstand inundation - frequency, duration, timing of and embryo development stage

Further research in these fields will lead to a fuller understanding of the habitat needs of Oregon turtles and a more comprehensive management plan to secure their futures.

\section{Management Document}

\section{Turtle Habitat Summary \& Management Recommendations}

Efforts to improve turtle habitat should prioritize sites that meet guidelines laid out in the Oregon Native Turtle Working Group Priority Turtle Conservation Areas (PTCA) (Appendix E). These sites have turtles with known age class diversity and nesting activity and are considered 'anchor habitat' for one or both of Oregon's two native turtle species. Assessments should be made at each site on the state of the habitat appropriate for each life stage (Adult, Nesting, Overwintering, Juvenile) ensuring that the populations have the resources necessary to maintain a healthy self-sustaining population through time. Larger population scale requirements including landscape connectivity and competition with non-native species can be dealt with once a framework for ensuring suitable habitat features has been established.

\section{Adult Habitat}

\section{0m Buffer}

Turtles have survived for millions of years through a variety of climatic conditions and threats. Their instinct to avoid predators often preempts their need to complete the basking activities required for their proper metabolic function. In areas with regular human activity, creating conditions that allow turtles to live without regular disturbance is essential for long-term turtle habitation. Creating and maintaining spaces with high levels of solar exposure with a selection of basking structures with a minimum of 40m distant from human activities allows turtles the opportunity for uninterrupted basking activity necessary for healthy turtle populations (Polich et al., 2016). A dense riparian edge, serving as a visual and physical barrier between turtles and areas of human activity, can be used to supplement sites with space limitations, but is not ideal.

Sites where turtles are constantly disturbed from their basking activities may not be turtle sites for long. Figure 1 depicts a successful buffer using a riparian barrier at least $3 \mathrm{~m}$ deep and $150 \mathrm{~m}$ long that sufficiently supplements the $40 \mathrm{~m}$ buffer area from human disturbance. 


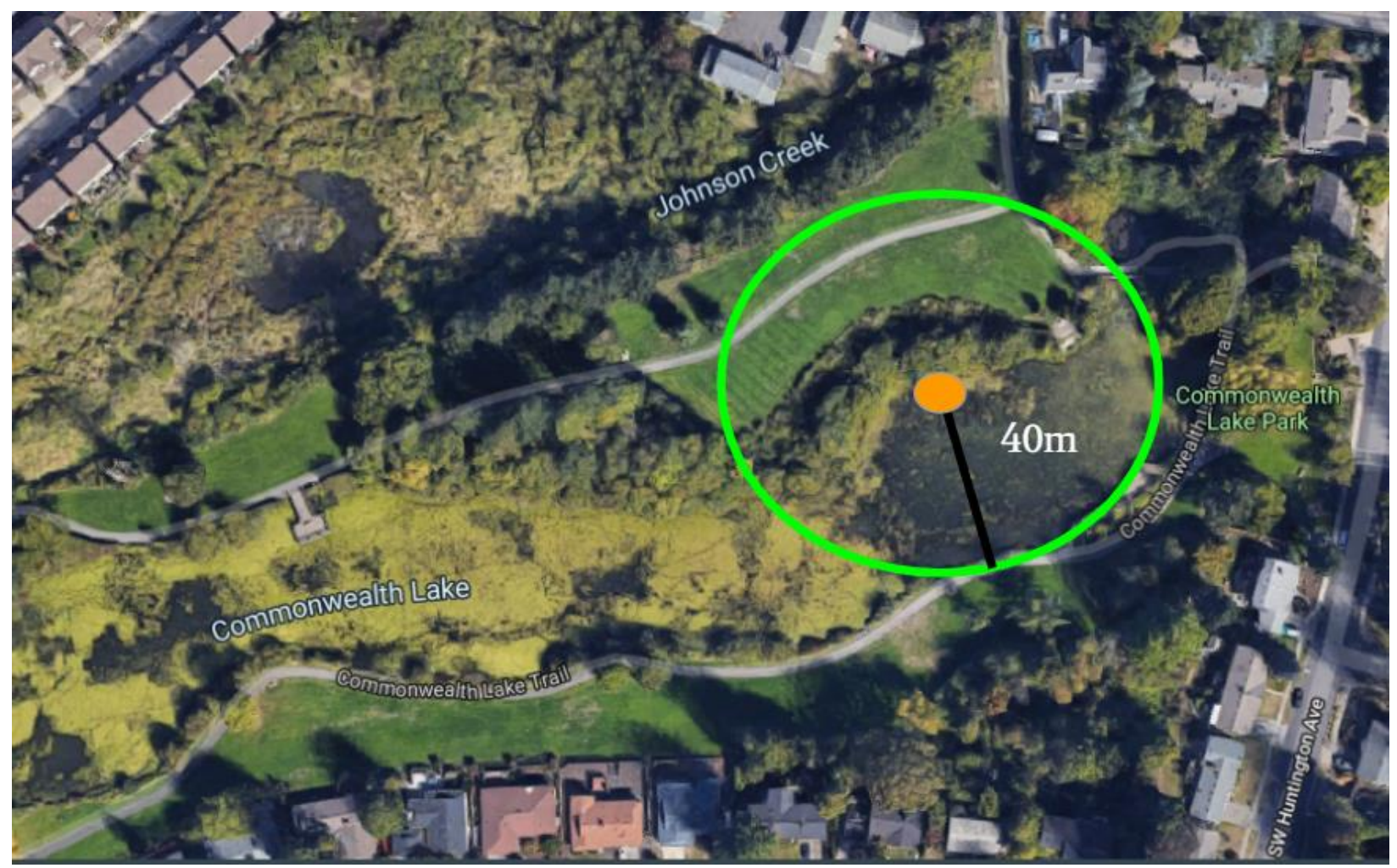

Figure 1: Illustrated photo of minimal $40 \mathrm{~m}$ buffer area required by turtles. A dense riparian buffer can supplement the buffer when space is at a premium.

\section{Artificial Basking Structures}

Supplemental basking structures can be installed when a dearth of basking areas is present. Ideal placement for adult and larger juvenile turtles will be in areas of high solar exposure and anchored at a distance from shore as habitat for adult turtles.

A variety of designs are regularly used, but a rectangular floating base of ABS piping is most stable and durable for long-term installation. Recommendations for semi-permanent basking structure placement include:

- ABS piping resistant to UV deterioration

- Symmetrical design for long-term flotation

- Flexible rubber connectors between planks and platform (old bike tires cut into 6" strips)

- Cinderblock anchor with $1 / 2$ " metal cable long enough to float at high water events but not so long as to become entangled

Turtle basking structure recipe from Smithers 2015 at the end of Appendix A. 


\section{Nesting}

Ideal nesting areas are adjacent to aquatic habitat hosting adult turtles as well as complex juvenile habitat. Open areas lacking canopy cover, with sparse vegetation, and suitable substrate are crucial for source turtle populations. Solutions will vary from site to site, but many turtle sites in this study area can be improved with low cost and basic remedies.

\section{Nesting Mounds}

Recommended substrate mixes from Oregon Turtle Best Management Practices are:

- Fine Clay: $25 \%$ or less

- Loam: $25 \%$

- Sand: $25-50 \%$

- Small aggregate: $25 \%$ or less

Appropriate nesting substrate can consist of a range of proportions but should not support dense vegetation. Sites should be placed in areas of high solar exposure at least $20 \mathrm{~m}$ from high human use areas. Mounding material can be appropriate when space is at a premium. Placing several mounds at different locations around turtle sites will give them options to select their own nest site. These mounds can improve nesting conditions atop former roadbeds and raise marginal nesting habitat above flood levels at urban sites with impassable barriers limiting available area (ODFW, 2015).

\section{Seasonal Trail Closures}

With the knowledge that high levels of pedestrians ( $>5$ pedestrians/hour) may be limiting turtle nesting, sites with potential nesting areas near regular human traffic could be managed with trail closures. Similar to seasonal closures for nesting birds and sea mammals, giving turtles undisturbed time and space to nest may give remnant populations a chance to bolster their numbers. This tactic would be site specific and could be implemented as a closure for the months of June \& July. Evening closures (1700-0000) during the nesting season could also be sufficient.

\section{Nest Caging}

Protecting nests requires communication and permitting from ODFW. While potentially effective at increasing population recruitment, this step should only be taken with a proper management plan in place as any nest protected needs regular and frequent monitoring during the incubation period and until hatchling emergence. Ideally, long-term native turtle populations will be self-sustaining and require no outside human interference, but in the short-term caging several nests a year could help ensure some hatchlings have a better chance to survive to emerge and become juveniles. 
Juvenile

Turtles under 4 years old or smaller than $12 \mathrm{~cm}$ carapace length are categorized as juveniles. Juvenile turtles were not the focus of this study but compose the largest data gap of any age class of turtles. Increasing juvenile survival rate is crucial to population recruitment in part because juvenile mortality rate is very high (Ritchie et al., 2009). Among many known predators are American bullfrogs (Lithobates catesbeiana), Great blue herons (Ardea herodias), and nonnative fish among others (Hays et al., 1999). They require complex habitat to shelter from their many predators as their mortality rates have been reported as nearly as high as nest depredation rates in some studies (Parrott et al, 2010). Microbasking structures in scale with the smaller dimensions of juvenile turtles are appropriate and necessary to decrease mortality rates and increase invertebrate refugia, increasing the turtle food supply.

\section{Small Woody Debris (SWD) Structures}

The generally degraded and simplified habitat is characterized by low amounts of habitat refugia, and, therefore, high risk of depredation. Contemporary river systems and lentic habitats have been highly modified and often lack riparian trees and shrubs, which would naturally recruit branches and debris into the system. Adding small piles of woody debris staked down along pond edges at a depth of $0-2 \mathrm{~m}$ can return complexity to simplified systems. The broad depth profile will ensure habitat is present throughout the year with varying water levels. Installation of SWD structures are frequently coupled with native aquatic vegetation transplants, which adds additional structured habitat to the system for the benefit of turtles and, potentially, other wildlife. 


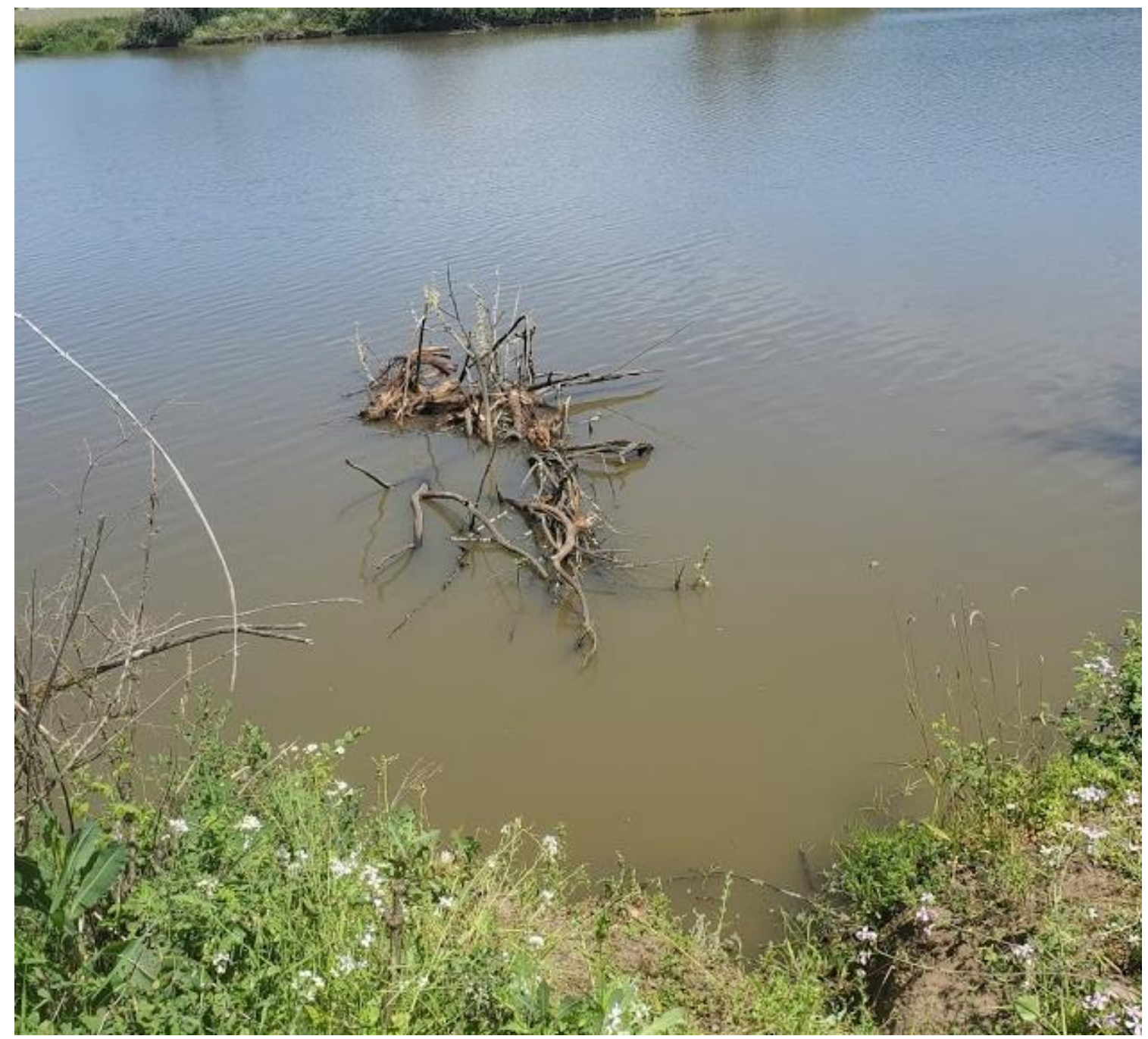

Figure 2: Small Woody debris structure installation (Photo credit: J. Holley, 2020).

\section{Connectivity}

\section{Off-channel Habitat}

On a larger scale, the simplification of river systems has greatly decreased off-channel floodplain habitat (Figures $1 \& 2$ ). Naturally created oxbow ponded habitat historically was ideal juvenile and overwintering turtle habitat and is now rare on the landscape. Looking for opportunities to reconnect the floodplain to the river will allow natural hydrology patterns to return with the assistance of American beaver. 


\section{Terrestrial Access}

Turtles require terrestrial areas for overwintering habitat, nesting, aestivation, and migration to other habitats. Ensuring that there are areas containing an ample duff layer accessible for meeting these diverse needs is essential for long-term population viability.

\section{Basking Structures}

Supplemental basking structures can be installed when insufficient natural basking structures are present. A variety of designs are regularly used. Smithers 2015 instructions for a basking structure are included below. Recommendations for aspects of semi-permanent basking structure placement include:

- ABS piping resistant to UV deterioration, suggested color: black or other dark color

- Symmetrical design for long-term flotation

- Flexible rubber connectors between planks and platform

- Cinderblock anchor with $1 / 2$ " metal wire long enough to float at high water events

\section{Competition \& Predator Control}

\section{Slider Patrol}

Most turtle sites in the Portland Metro region have populations of T. scripta elegans including at least 16 of the 25 sites used in this study. Non-native turtles utilize similar resources to our native turtles, except more efficiently (Holley, 2016)). At sites with high numbers of T. scripta elegans, trained volunteers or employees walk daily through nesting areas during nesting season (June \& July) between 1000 and 1200 will likely yield nesting female sliders, which can be removed from the wild and minimize long-term competition with our native turtles. Note: All species of sliders (Trachemys sp.) and other invasive turtle species are regulated by ODFW as Prohibited Nonnative Wildlife and may not be possessed live or transported in Oregon without a permit from ODFW (OAR 635-056).

\section{Bullfrog Population Control}

While the American bullfrog is thoroughly established at nearly every turtle site in Oregon and the number one predictor of turtle presence at a site, they are known to be consumers of juvenile turtles (Holley, 2016; Samara Group, 2021). Recent efforts of population control targeting bullfrogs have nearly achieved eradication at Yosemite National Park (Kamoroff et al, 2019). While not effective if performed in a random manner, reducing bullfrog populations (all age classes including eggs) will decrease surplus mortality and raise the overall survival rates of juvenile turtles. 


\section{How to make a turtle platform:}

(1) - ten foot long piece of $3^{\text {" }}$ ABS pipe "cut into 2 three foot lengths and 2 two foot lengths

(1) - PVC cement, 1 pint

(4) - 3" ABS elbows

(3) $-8^{\prime} \times 1^{\prime \prime} \times 6^{\prime \prime}$ cedar fencing

"cut one cight foot piece into six 16 " lengths for ramps

"cut one more 16 "length from each of the remaining two $8^{\circ}$ pieces

*cut the remaining two long pieces in half, yielding $4-40^{* \prime}$ sunning decks
(1) - old bicycle tire "cut $\sim 6$ " lengths to connect ramps to deck ends

(1)-box of \#8 woodscrews $1 \frac{1 / 2}{H}$ long

(1)-box of \#8 woodscrews $\% 4^{*}$ long

(2) - $-40^{-1}$ lengths of $1^{\prime \prime} \times 2^{\prime \prime}$ (rough cut wood)

(1) - large roll of galvanized plumber's tape

(1) - small container of gorilla glue

(1)- small roll of mechanic wire

1. On a flat surface, Use PVC cement to connect the ABS pipe and elbows together to form a rectangle.

2. Glue (gorilla glue) each 40 " length of 1 " $x 2$ " wood to the top of each long side of the ABS pipe rectangle. Compress the wood and PVC together for 1-2 hours after gluing to assure a strong connection.

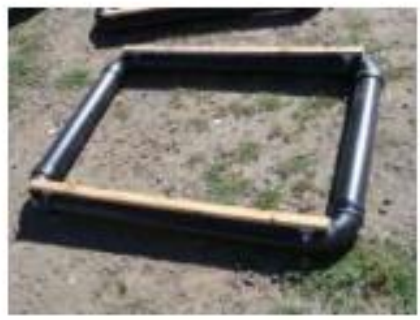

3. Place the four 40 " deck pieces across the top of the rectangle platform, with both ends resting on the 1 "x2" wood strips. Evenly space the four deck pieces across the top with 5-6 inches between them. Screw (1 1/2") them at both ends into the two 1 " $x 2$ "wood strips. Take care not to puncture the plastic pipe.

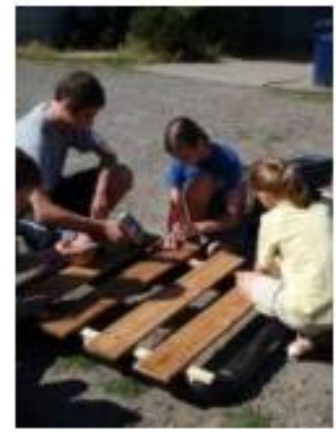


4. Connect the ramps to the end of the deck pieces with the plumber's tape and rubber strips cut from the bicycle tire. First attach plumber's tape with $3 / 4$ " screws onto the 40 " board pieces and attach ramps at approximately a 60 degree angle. Then add rubber strips on top of plumbers tape. The rubber strips will help the ramps last longer as the plumbers tape will likely degrade after a few months.

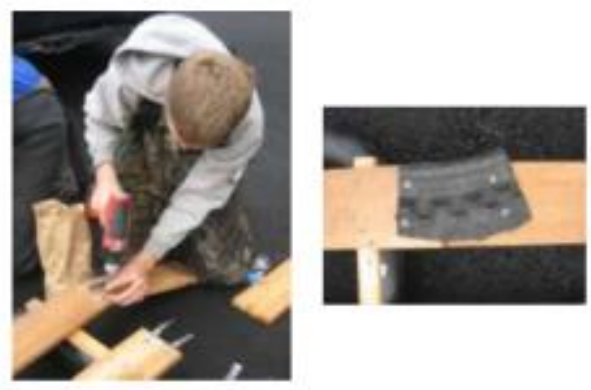

5. Ending results should look something like this!

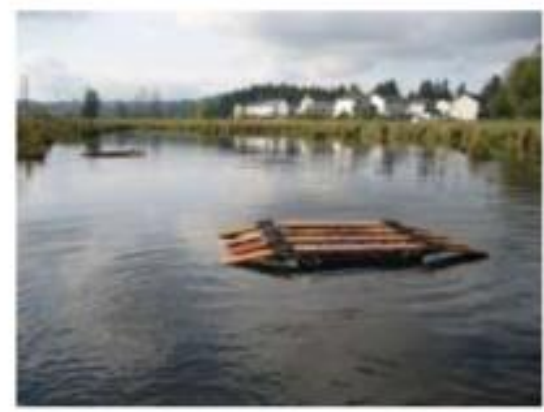




\section{Literature Cited}

Baldwin, E.A., Marchand, M.N., \& Litvaitis, J.A. 2004. Terrestrial habitat use by nesting painted turtles in landscapes with different levels of fragmentation. Northeastern Naturalist, 11(1): 41-48.

Barela, K.L. 2014. Mapping the Western pond turtle (Actinemys marmorata) and painted turtle (Chrysemys picta) in Western North America. Northwestern Naturalist, 95(1): 1-12.

Boyer, D.R. 1965. Ecology of the basking habit in turtles. Ecology: 99-118.

Bury, R.B. \& Germano, D.J. 2008. Actinemys marmorata (Baird and Girard 1852): Western pond turtle, Pacific pond turtle. Conservation Biology of Freshwater Turtles and Tortoises: Chelonian Research Monographs (ISSN 1088-7105) No. 5.

Bury, R.B., Hartwell Jr., H.W., Germano, D.J. \& Ashton, D.T. 2012. Western pond turtle: Biology, sampling techniques, inventory and monitoring, conservation, and management: Northwest Fauna No. 7. The Society for Northwest Vertebrate Biology. 128.

Cadi, A. \& Joly, P. 2003. Competition for basking places between the endangered European pond turtle (Emys orbicularis galloitalica) and the introduced red-eared slider (Trachemys scripta elegans). Canadian Journal of Zoology, 81(8): 1392-1398.

Cadi, A. \& Joly, P. 2004. Impact of the introduction of the red-eared slider (Trachemys scripta elegans) on survival rates of the European pond turtle (Emys orbicularis). Biodiversity and Conservation 13: 2511-2518.

Carrière, M.A., Rollinson, N., Suley, A.N. \& Brooks, R.J. 2008. Thermoregulation when the growing season is short sex: Biased basking patterns in a northern population of painted turtles (Chrysemys picta). Journal of Herpetology, 42(1): 206- 209.

Congdon, J.D., Dunham, A.E. \& Van Loben Sels, R.C. 1994. Demographics of common snapping turtles (Chelydra serpentina): Implications for conservation and management of long-lived organisms. American Zoologist, 34(3): 397-408.

Congdon, J., Breitenbach, G., Van Loben Sels, R.C. \& Tinkle, D. 1987. Reproduction and Nesting Ecology of Snapping Turtles (Chelydra serpentina) in Southeastern Michigan. Herpetologica, 43(1): 39-54.

Congdon, J.D. \& Tinkle, D.W. 1982. Reproductive energetics of the painted turtle (Chrysemys picta). Herpetologica, 38(1): 228-237.

Delaney, D.M., Janzen, F.J. \& Warner, D.A. 2016. Nesting stage and distance to refuge influence terrestrial nesting behavior of Painted Turtles (Chrysemys picta). Canadian Journal of Zoology, 95(11): 837-841.

Delaney, D.M. \& Janzen, F.J. 2020. Risk-sensitive maternal investment: An evaluation of parent-offspring conflict over nest site choice in the wild. Animal Behaviour, 163: 105-113.

Ernst, C. \& Zug, G. 1994. Observations on the Reproductive Biology of the Spotted Turtle, Clemmys guttata, in Southeastern Pennsylvania. Journal of Herpetology, 28(1), 99-102. 
Frye, A. B., Hardy, K., Hedrick, A.R. \& Iverson, J.B. 2017. Factors affecting nesting times in the painted turtle Chrysemys picta in Nebraska. Chelonian Conservation and Biology, 16(1): 44-51.

Gibbons, J.W. 1968a. Reproductive Potential, Activity, and Cycles in the Painted Turtle, Chrysemys picta. Ecology, 49: 399-409.

Gibbons, J. \& Nelson, D. 1978. The Evolutionary Significance of Delayed Emergence from the Nest by Hatchling Turtles. Evolution, 32(2): 297-303.

Gibbons, J.W., Scott, D.E., Ryan, T.J., Buhlmann, K.A., Tuberville, T.D., Metts, B.S., Greene, J.L., Mills, T., Leiden, Y., Poppy, S. \& Winne, C.T. 2000. The Global Decline of Reptiles, Déjà Vu Amphibians: Reptile species are declining on a global scale. Six significant threats to reptile populations are habitat loss and degradation, introduced invasive species, environmental pollution, disease, unsustainable use, and global climate change. BioScience, 50(8): 653-666.

Hammond, K.A., Spotila, J.R., \& Standora, E.A. 1988. Basking behavior of the turtle Pseudemys scripta:Effects of digestive state, acclimation temperature, sex, and season. Physiological Zoology: 69-77.

Hays, D.W., McAllister, K.R., Richardson, S.A. \& Stinson, D.W. 1999. Washington state recovery plan for the western pond turtle. Wash. Dept. Fish and Wild., Olympia.

Heppard, J.M. 2018. Impact of human disturbance on the behavior and physiology of the endangered ringed sawback turtle (Graptemys oculifera). Electronic Theses and Dissertations. 1277.

Holland, D.C. 1994. The Western pond turtle: Habitat and History. Oregon Department of Fish and Wildlife. Portland, OR.

Lambert, M.R., McKenzie, J.M., Screen, R.M., Clause A.G., Johnson, B.B., Mount, G.G., Shaffer, H.B. \& Pauly, G.B. 2019. Experimental removal of introduced slider turtles offers new insight into competition with a native, threatened turtle. PeerJ: 7444.

Marchand, M.N. \& Litvaitis, J.A. 2004. Effects of Habitat Features and Landscape Composition on the Population Structure of a Common Aquatic Turtle in a Region Undergoing Rapid Development. Conservation Biology, 18: 758-767.

Mitchell, T.S. \& Janzen, F.J. 2019. Substrate Influences Turtle Nest Temperature, Incubation Period, and Offspring Sex Ratio in the Field. Herpetologica 1 March 2019; 75 (1): 57-62.

Moore, M.J.C. \& Siegel, R.A. 2006. No place to nest or bask: Effects of human disturbance on the nesting and basking habits of yellow-blotched map turtles (Graptemys flavimaculata). Biological Conservation, 130(3): 386-393.

Morlan, J.C. 2000. Summary and current status and health of Oregon's freshwater wetlands. The Oregon State of the Environment Report 2000. Oregon Progress Board, Salem. 45-52.

Murphy, K.M., Bodensteiner, B.L., Delaney, D.M., Strickland, J.T. \& Janzen, F.J. 2020. Nest Temperatures Predict Nest Emergence of Painted Turtle (Chrysemys picta) Offspring. Chelonian Conservation and Biology, 19(1): 72-77. 
ODFW. 2015. Guidance for conserving Oregon's native turtles including best management practices. Oregon Dept. of Fish and Wildlife. Pp. 99. https://www.oregonturtles.com/guidance.html

ODFW Oregon Conservation Strategy. 2016. Oregon Department of Fish and Wildlife, Salem, Oregon.

Packard, G.C., Packard, M.J., Miller, K., \& Boardman, T.J. 1987. Influence of moisture, temperature, and substrate on snapping turtle eggs and embryos. Ecological Society of America, 68(4): 983-993.

Parrott, A. \& Logan, D.L. 2010. Effects of temperature variation on TSD in turtle (C. picta) populations. Ecological Modelling, 221(10): 1378-1393.

Pittfield, T. \& Burger, J. 2017. Basking habitat use and response of freshwater turtles to human presence in an urban canal of Central New Jersey. Urban Ecosystems, 20: 449-461.

Polich, R.L. \& Barazowski, M. 2016. Flight Initiation Distance in a Freshwater Turtle, Chrysemys picta. Chelonian Conservation and Biology, 15(2): 214-218.

Riensche, D.L., Riensche, S.K., Riensche, R.E. \& Hoffman, R. 2019. Habitat use, movement patterns, and nest site selection by Western pond turtles (Actinemys marmorata) in a managed central California rangeland pond. Society for Northwestern Vertebrate Biology, 100(2): 90.

Ratterman, R.J. \& Ackerman, R.A. 1989. The water exchange and hydric microclimate of painted turtle (Chrysemys picta) eggs incubating in field nests. Physiological Zoology, 62(5): 1059-1079,

Ritchie, E.G. \& Johnson, C.N. 2009. Predator interactions, mesopredator release and biodiversity conservation. Ecology Letters (12): 982-998.

Rosenberg, D.K. 2013. Post-emergence behavior of hatchling Western pond turtles (Actinemys marmorata) in Western Oregon. The American Midland Naturalist, 169(1), 111-121.

Rowe, J.W. \& Dalgarn, S.F. 2009. Body temperature variation during nesting forays in Midland painted turtles, Chrysemys picta marginata, in Michigan. Chelonian Conservation and Biology, 8(2): 168-172.

Samara Group. Unpublished. Northwestern pond turtle assessment for Oregon Department of Fish and Wildlife.

Selman, W., Qualls, C. \& Owen, J.C. 2013. Effects of human disturbance on the behavior and physiology of an imperiled freshwater turtle. The Journal of Wildlife Management, 77: 877-885.

Smithers, A. P. 2015. Management plan for Western painted turtle (Chrysemys picta bellii) at Fairview Creek Headwaters. Submitted to the City of Gresham and Portland State University.

Spencer, R.J. 2002. Experimentally testing nest site selection: Fitness trade-offs and predation risk in turtles. Ecology, 83: 2136-2144.

Steen, D. A. \& Gibbs, J. P. 2004. Effects of roads on the structure of freshwater turtle populations. Conservation Biology, 18(4): 1143-1148. 
Swihart, R.K., Lusk, J.J., Duchamp, J.E., Rizkalla, C.E. \& Moore, J.E. 2006. The roles of landscape context, niche breadth, and range boundaries in predicting species responses to habitat alteration. Diversity and Distributions, 12: 277-287.

USDA. 2014. Soil survey field and laboratory methods manual: Soil survey investigations report No. 51, Version 2.

Vander Haegen, W.M., Clark, S.L., Perillo, K.M., Anderson, D.P., \& Allen, H.L. 2009. Survival and causes of mortality of head-started western pond turtles on Pierce National Wildlife Refuge, Washington. The Journal of Wildlife Management, 73(8): 1402-1406.

Wilson, D.S., Tracy, C.R. \& Tracy, C.R. 2003. Estimating age of turtles from growth rings: A critical evaluation of the technique. Herpetologica, 59(2): 178-194. 


\section{Appendix A: Original protocol used for May 2019 volunteer trainings}

\section{Nesting Surveys}

Sites to be included in nesting surveys were determined by having observed presence of $>1$ native turtle or other outstanding turtle habitat feature. Areas of high solar exposure were identified and surveyed in a methodical gridlike manner 2-15 times per month (twice a week was the goal) from May $30^{\text {th }}$ through July $31^{\text {st }}, 2019$ by individuals trained in identifying signs of turtle nesting activity. Surveyors recorded GPS points and causes of likely turtle nesting activity (Intact nest, depredated nest, test dig, or turtle on land).

Little data was available at most sites as to where historic turtle nesting activity has occurred. About half the sites had records of depredated nest locations. More than 50 volunteers were trained at two field training sessions in May 2019 to assist in data collection. Protocol for data collection included recording start time, surveyor names, GPS locations of likely turtle nesting activity, type of nesting activity (intact nest, depredated nest, test dig (no eggs were laid-disturbed or hit hard substrate) or turtle on land), number of humans and dogs observed during the survey, end time, and other notable information. An application was recommended to record GPS locations (My GPS Location) but was not compatible with Apple and other phones and could be recorded in any format.

Surveys were repeated at each site at least twice during the 2020 nesting season.

Surveys were conducted only on land with landowner/manager permission obtained so the amount of nesting at adjacent private management sites is unknown and analyses were performed using only known information.

Intact nests were caged with 3/4" hardware cloth to prevent depredation. Cages were removed in October 2019 and visited monthly to observe for hatchling emergence times. All nests were revisited and excavated in mid-May 2020 to determine the fate of the occupants.

Population estimates were used to quantify an approximate native turtle population at each site. Population estimates for each site include only native turtle populations. Minimum population values were used at sites without Mark-Recapture data. This metric is defined as the largest number of turtles seen at a site on a single visit as the minimum population residing at that location. 


\section{Appendix B: Aquatic Complexity Surveys \& Methods}

\section{Juvenile Habitat}

Turtles are considered juvenile when they have a carapace length less than $10 \mathrm{~cm}$, generally about 4 years old. They are cryptic in their activities as they are prey for a large number of predators including: American bullfrogs (Lithobates catesbeiana), Great blue herons (Ardea herodias), raccoons (Procyon lotor), largemouth bass (Micropterus salmoides) and smallmouth bass (Micropterus dolomieu) and non-native fish among others. They are difficult to study as they are difficult to catch, bask for shorter periods of time and in different places than adults. In Oregon, it is thought that increasing complexity in shallow water habitat may increase survival rates. This complexity can be broken into two primary parts: aquatic vegetation and small woody debris.

Underwater complexity and depth profile are likely important components of juvenile turtle survival. Turtles likely use shallow water sites $(<0.5 \mathrm{~m})$ for surface basking as the water is generally warmer. This is also habitat with a high usage rate by two of their main predators: the bullfrog and great blue heron.

Aquatic habitat surveys were conducted in 2020 at a limited number of sites both with known turtle populations and, likely, currently uninhabited by turtles in an attempt to better quantify and understand the parameters of juvenile painted turtle habitat.

All sites except for one contained abundant native submergent vegetation in depths $>0.5 \mathrm{~m}$. Quantifying woody debris and complexity are challenging as they are subjective. Either native Elodea canadensis or Ceratophyllum demersum were dominant at all sites except one which had virtually no aquatic vegetation in an old agricultural pond.

Future studies should repeat the surveys in the spring when young hatchlings are first emerging and likely naive to many dangers they face and aquatic vegetation is at its minimum, midsummer when vegetation is vigorous, and again in autumn before most species die back for winter.

RECOMMENDATION: To increase complexity for juvenile turtles Small Woody Debris structures (SWD) can be installed. Simple in materials, two 3-4m branches with multiple branches are placed with the butt ends facing oppositely. Smaller branches can also be woven into this framework giving a selection of microhabitat refugia. V-shaped branches can be driven into the substrate to prevent the structure from floating away. Aquatic vegetation can also be transplanted to increase the complexity of the habitat. 


\section{Aquatic Complexity Surveys}

In autumn 2020, a stratified, random sampling of aquatic vegetation and small woody debris was performed at a selection of sites across the spectrum of turtle occupancy and nesting activity. Sampling points were centered around known nesting locations, when possible. At least 10 measurements were taken at each site using one meter square quadrats, five within $3 \mathrm{~m}$ of shore, another 5 between $1-2 \mathrm{~m}$ from shore, and, if needed, a third transect of 5 samples documenting potential juvenile turtle habitat conditions. Data on presence and quality of small woody debris presence on the surface and at $0.5 \mathrm{~m}$ depth, individual aquatic plant species found, $\%$ open water, $\%$ emergent, $\%$ submergent, and \% floating vegetation was performed to determine densities and types of vegetation associated with juvenile turtle occupancy.

Sites for aquatic vegetation surveys were selected to include 1) sites with turtles and known nesting activity, 2) turtles and no known nesting activity, and 3) no turtles or nesting activity known. To better understand the diversity of existing conditions and which factors may be limiting turtle occupancy and population recruitment. Terrestrial substrate sampling was taken from select sites at known nesting areas including known nesting sites and random samples within appropriate areas of high solar exposure.

\section{Juvenile Aquatic Habitat Survey Information \& Methods Portland State University jamespholley@gmail.com} 19 October 2020

Juvenile turtles are highly vulnerable to predation until they reach approximately $60 \mathrm{~mm}$ at about 3 years old. Anecdotal evidence indicates that increased levels of habitat complexity with varying depth profiles $(0-3 \mathrm{~m})$ at locations adjacent to known turtle nesting habitat increase the likelihood of young turtles reaching adulthood. Habitat including aquatic vegetation and small woody debris complexity at depths greater than $1 \mathrm{~m}$ are likely advantageous for young turtles by excluding landing areas for known predators such as Great blue heron and common shallow water American bullfrog basking areas. Quantifying juvenile turtle habitat is challenging due to low detection probability of juvenile age classes and lack of general agreement on the components of quality juvenile brood habitat.

Portland State University Master's of Environmental Management candidate James Holley is collecting data for use in performing an analysis of native turtle habitat in the Lower Willamette Basin. He has performed turtle presence surveys throughout the Portland Metro region since 2011 , turtle nesting surveys at 25 sites in 2019 \& 2020 and is collecting data on aquatic vegetation species and densities to add further detail to the features of likely juvenile turtle habitat in the Pacific Northwest; in addition to historical and academic research. 
A stratified, random sampling of at least 5 , one meter square quadrats will be performed in aquatic habitat near points of turtle nesting activity. Data on presence and quality of small woody debris complexity, individual aquatic plant species found, \%open water, \%emergent, \%submergent, \%floating vegetation to determine densities and types of vegetation associated with juvenile turtle occupancy. A measure of small woody debris, floating, and emergent vegetation will be taken at the surface and submergent vegetation density and small woody debris complexity will be measured at a depth of $0.5 \mathrm{~m}$ in the same one square meter quadrat. Data on human and dog usage of turtle nesting sites will also be recorded during surveys. Surveys will be performed in the Fall 2020 at selected sites around the Portland Metro area. Surveys will (ideally) be repeated in Spring 2021 to account for the seasonal variation in plants. Sampling locations will be selected as the closest water habitat to known or potential turtle nesting habitat. This survey of aquatic vegetation will attempt to better quantify the required characteristics of effective juvenile turtle habitat broken into two primary types:

1. Small Woody Debris (SWD): microbasking structures and safe havens ranked from 0-5 with 0 being no woody debris/sparse vegetation and 5 being high complexity and/or abundance with varying microhabitat sizes and structures.

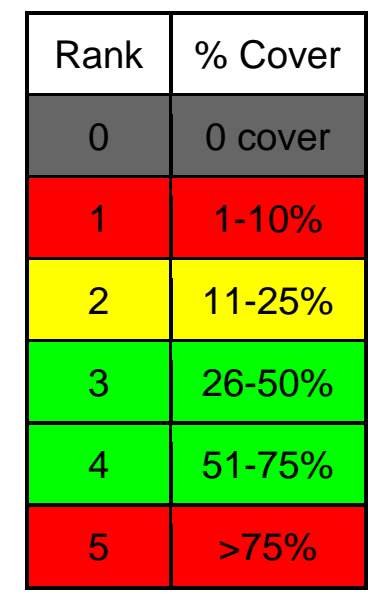

2. Aquatic Vegetation Density: Measure the composition and density of vegetation below the high water level of the water body. Vegetation will be broken into 5 clades totalling $100 \%$ of the space. [\%Persistent \& Non-persistent Emergent Vegetation will likely be combined for this survey]
a. SWD surface rating
b. \% Open Water
c. \% Floating Vegetation
d. \% Emergent Vegetation
e. \% Submergent Vegetation @0.5m
f. SWD rating @0.5m
g. Maximum Depth of quadrat 
Individual species will be recorded, as possible, with estimated percent cover per $\mathrm{m}^{2}$. Notes will be made as to the native or non-native origin of the vegetative composition.

\section{Equipment \& Safety}

A safe atmosphere with complete discussion of all potential dangers will occur before fieldwork begins at any site. Chest waders and a life vest will be worn into the wetland areas to collect samples. A 1 square meter PVC quadrat will be used to quantify the vegetation density in a standardized manner. Clipboards and pens will be used to record data All equipment will be sanitized with alcohol between users and sites. Waders will be allowed to dry completely between basins. All persons present will observe strict social distancing and mask-wearing protocols with a mask being worn whenever someone is within $5 \mathrm{~m}$ of another human. All parties will provide their own transport. High visibility vests will be given to all present for the surveys. Masks and hand sanitizer will be available. No equipment will be left at the sites following surveys.

\section{Methods}

A quadrat with an area of $1 \mathrm{~m}^{2}$ will be placed in a stratified random location with 5 samples taken within $3 \mathrm{~m}$ of shore over a distance of $30 \mathrm{~m}$ and 5 samples were taken $3-6 \mathrm{~m}$ from shore in likely juvenile turtle habitat defined as the closest point of persistent water to a verified nesting attempt. Additional surveys in increments of $3 \mathrm{~m}$ distances from shore will be performed as necessary. The survey transect will spread $15 \mathrm{~m}$ from this point in both directions perpendicular to the shoreline. Adjustments for shoreline complexity and contours will be made in a method applicable to plowing an agricultural field.

Each quadrat will measure vegetation and complexity by clade: floating, emergent, submergent and small woody debris (complexity relative to the size of a juvenile turtle). Individual species will be quantified where possible.

Area covered will be assessed for Individual plant species will be recorded where possible and sample specimens will be taken and housed at the Portland State Herbarium. The overall area will be assessed as a percent (\%) in 5 categories (listed above). The $\sim 30 \mathrm{~m}$ length along the shore will be graded for small woody debris structure on a scale of $0-5$ with 0 being no complexity and 5 being Abundantly Complex. A rank of 3 indicates likely sufficient cover for increased juvenile turtle survivorship.

Small woody debris presence will be ranked according to habitat quality on a scale of 0 (no small woody debris) to 5 (abundant/complex). 


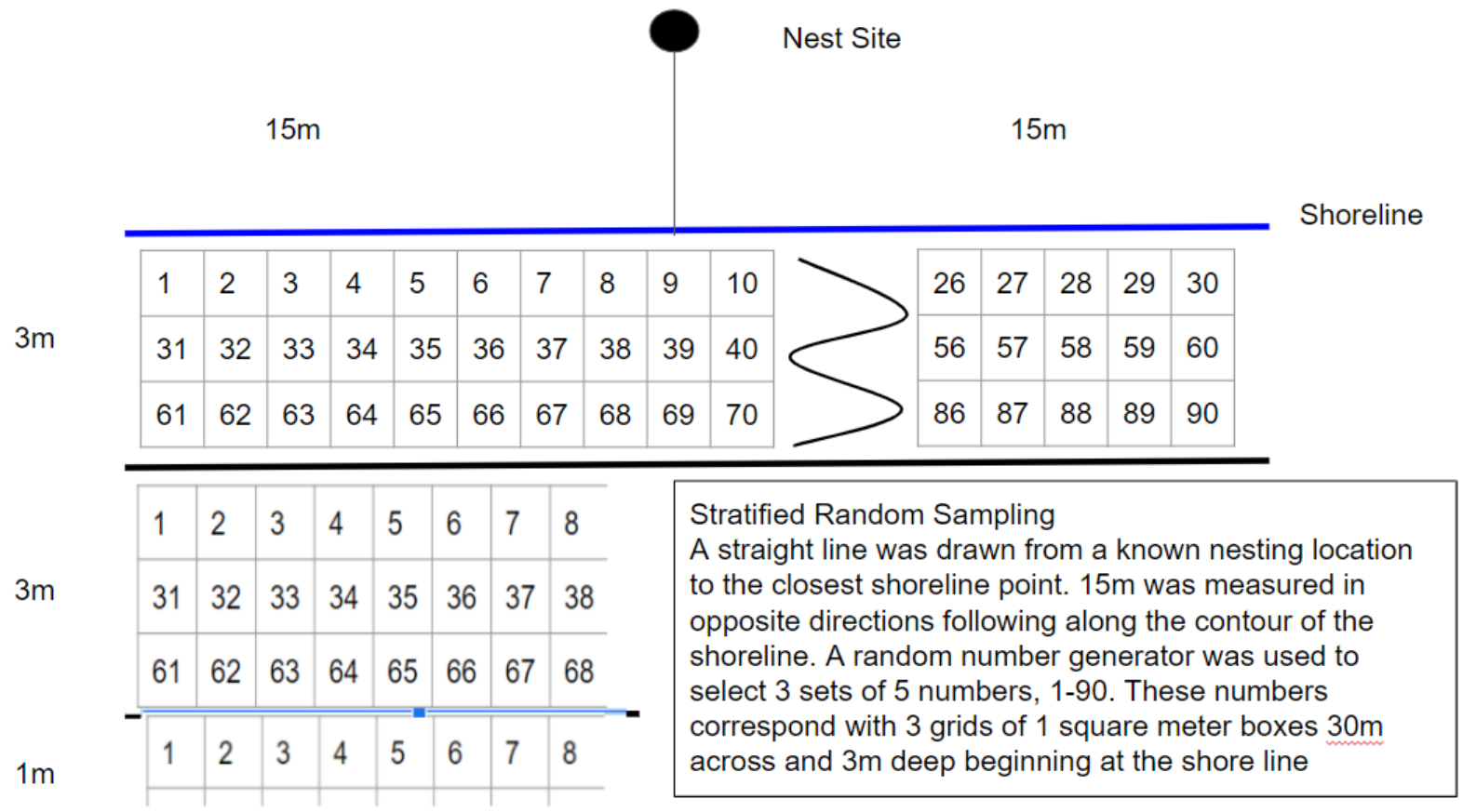

Figure _: Schematic of proposed stratified random aquatic vegetation sampling 
Appendix C: ODFW Turtle Nesting Form

Email received from Susan Barnes, ODFW on 4/16/2020
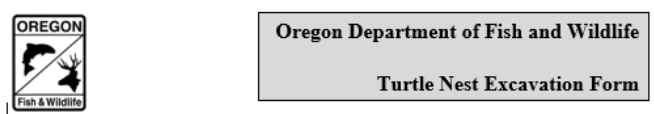

SECTION A: LocATION \& CoNTACT INFoRMATION
\begin{tabular}{|l|l|}
\hline Site Name, Sub-Area \& Location (address): & Nest \# (if applicable); \\
\hline Lat / Long (include Datum): & County: \\
\hline Watershed / Sub-Watershed: & Time of Nesting: \\
\hline Date of Nesting: & Name/Affliation / Contact Info of Person who Observed Turtle Nesting: \\
\hline Date of Excavation: \\
\hline Name / Affiliation / Contact Information of Nest Excavator: \\
\hline Reason For Excavation:
\end{tabular}

ФSECTION B: Nest SITE ChARACTERISTICS

Nesting Substrate:

\begin{tabular}{|l|l|l}
\hline Gravel Present (circle one): YES $\quad$ NO & Bark Chips Present (circle one): YES NO
\end{tabular}

General Setting of Nest Site (circle all that apply):

Adjacent to Road or Trail Natural Habitat Backyard Other

\begin{tabular}{|l|l|}
\hline \% Canopy Cover: & \% Vegetative Ground Cover: \\
\hline
\end{tabular}

\begin{tabular}{|l|l|l|}
\hline \% Canopy Cover: & \% Vegetative Ground Cover: \\
\hline $\begin{array}{l}\text { Description of Vegetative Ground Cover (if any): i.e., species, } \\
\text { type. }\end{array}$ & Nest Site Aspect $(\mathbb{N}, N E, E$, etc.): \\
\hline
\end{tabular}

\begin{tabular}{|l|l|}
\hline Name of Closest Waterbody: & Distance to Water (m) at time of nest excavation: \\
\hline Distance to Water (m) at time of nesting activity (if lnown): \\
\hline
\end{tabular}

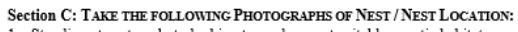

1. Standing at nest, a photo looking toward nearest suitable aquatic habitat.

2. Top down view of nest, with nest in center of photo and taken 2 feet from ground surface.
Section D: TURTLE INFoRMATION
\begin{tabular}{|l|l|}
\hline $\begin{array}{c}\text { Female Turtle was Captured (circle one): } \\
\text { YES NO UNK }\end{array}$ & $\begin{array}{l}\text { Turtle Species \& Unique Turtle ID\# (Notch \# \& } \\
\text { System,, PIT Tag \#): }\end{array}$ \\
\hline Turtle Capture Date \& Time: \\
\hline Final Disposition of Turtle:
\end{tabular}

Section E: Nest CHAMBer CHARActeristics

\begin{tabular}{|l|l|}
\hline Depth (cm) to Top Egg / Hatchling: & Depth (cm) to Bottom Egg/ Hatchling:
\end{tabular}

Section F: Nest ChaMrer Contents

\begin{tabular}{|c|c|c|c|c|c|c|}
\hline $\begin{array}{c}\text { Egg or } \\
\text { Hatchling \# }\end{array}$ & $\begin{array}{c}\text { Hatchling } \\
\text { or Eg Eg (nith } \\
\text { of withouth } \\
\text { embrov) }\end{array}$ & $\begin{array}{l}\text { Dead } \\
\text { or } \\
\text { Live }\end{array}$ & $\begin{array}{l}\text { Embryo- } \\
\text { Full, } \\
\text { Partial or } \\
\text { None }\end{array}$ & $\begin{array}{l}\text { Hatchling/ } \\
\text { Whale Egg } \\
\text { Weight (g) }\end{array}$ & $\begin{array}{c}\text { H CL or } \\
\text { Whole Eg } \\
\text { LulK }(\mathrm{mm})\end{array}$ & $\begin{array}{l}\text { Final Disposition / } \\
\text { Other Info }\end{array}$ \\
\hline 1 & & & & & & \\
\hline 2 & & & & & & \\
\hline 3 & & & & & & \\
\hline 4 & & & & & & \\
\hline 5 & & & & & & \\
\hline 6 & & & & & & \\
\hline 7 & & & & & & \\
\hline 8 & & & & & & \\
\hline 9 & & & & & & \\
\hline 10 & & & & & & \\
\hline 11 & & & & & & \\
\hline 12 & & & & & & \\
\hline 13 & & & & & & \\
\hline 14 & & & & & & \\
\hline 15 & & & & & & \\
\hline 16 & & & & & & \\
\hline 17 & & & & & & \\
\hline 18 & & & & & & \\
\hline 19 & & & & & & \\
\hline 20 & & & & & & \\
\hline
\end{tabular}

Other Comments / Info 


\section{Website Language: \\ What are Priority Turtle Conservation Areas?}

Priority Turtle Conservation Areas are sites with high ecological value that are essential for the conservation of native species in the Lower Willamette Valley. They are determined through a prioritization process which involves the review of turtle monitoring data (from basking, nesting and trapping survey efforts), threat assessments and habitat evaluations. Sites with detailed survey information showing successfully breeding populations are ranked with the highest priority as are sites with known native turtle presence that are well connected to or have the potential to be connected to the larger watershed/aquatic system. In general, sites that provide high quality habitat that on average allows a population to increase over time are considered the highest priority sites for designation as a PTCA.

\section{How will Priority Turtle Conservation Areas help turtles?}

The Priority Turtle Conservation Area designation helps turtles by setting priorities for habitat conservation and promoting positive action to safeguard vital turtle habitats. The identification of PTCAs is an important first step in larger turtle conservation initiatives. PTCA designation encourages local stewardship and advocacy, and is therefore a starting point for site-based conservation efforts. Stakeholders are included in the process at many levels. Conservation activities at PTCAs reflect the unique circumstances of each site (e.g. size, location, and ownership). For example, public areas may be conserved by open-space acquisition and by working with land managers to improve habitat management practices. Private lands may be conserved through public-private partnerships such as easements, and through landowner education.

\section{Priority Turtle Conservation Area Selection Criteria}

By definition, Priority Turtle Conservation Areas are sites that support:

1. Native turtle populations (Western painted turtle, Chrysemys picta belli; and/or Northwestern Pond Turtle, Actinemys marmorata)

2. Evidence of a successfully breeding population of one or both species of native turtles (through data collected via basking, nesting and/or trapping surveys)

3. The presence of the multiple habitat types required for healthy native turtle populations (basking, feeding, nesting, aestivation, overwintering).

4. Connection to or potential connection to the larger watershed/system - isolated populations may be considered, but the existence of or opportunities for connecting multiple sites across a watershed or aquatic system is ideal.

5. Populations of native turtles at the edge of their known or suspected range; these populations may have only a few individuals, but protection throughout the entire range of these animals is important for their conservation and may be prioritized. 


\title{
Appendix F Priority Turtle Conservation Areas
}

\author{
Website Language: \\ What are Priority Turtle Conservation Areas?
}

Priority Turtle Conservation Areas are sites with high ecological value that are essential for the conservation of native species in the Lower Willamette Valley. They are determined through a prioritization process which involves the review of turtle monitoring data (from basking, nesting and trapping survey efforts), threat assessments and habitat evaluations. Sites with detailed survey information showing successfully breeding populations are ranked with the highest priority as are sites with known native turtle presence that are well connected to or have the potential to be connected to the larger watershed/aquatic system. In general, sites that provide high quality habitat that on average allows a population to increase over time are considered the highest priority sites for designation as a PTCA.

How will Priority Turtle Conservation Areas help turtles?

The Priority Turtle Conservation Area designation helps turtles by setting priorities for habitat conservation and promoting positive action to safeguard vital turtle habitats. The identification of PTCAs is an important first step in larger turtle conservation initiatives. PTCA designation encourages local stewardship and advocacy, and is therefore a starting point for site-based conservation efforts. Stakeholders are included in the process at many levels. Conservation activities at PTCAs reflect the unique circumstances of each site (e.g. size, location, and ownership). For example, public areas may be conserved by open-space acquisition and by working with land managers to improve habitat management practices. Private lands may be conserved through public-private partnerships such as easements, and through landowner education.

\section{Priority Turtle Conservation Area Selection Criteria}

By definition, Priority Turtle Conservation Areas are sites that support:

1. Native turtle populations (Western painted turtle, Chrysemys picta belli; and/or Northwestern Pond Turtle, Actinemys marmorata)

2. Evidence of a successfully breeding population of one or both species of native turtles (through data collected via basking, nesting and/or trapping surveys)

3. The presence of the multiple habitat types required for healthy native turtle populations (basking, feeding, nesting, aestivation, overwintering).

4. Connection to or potential connection to the larger watershed/system - isolated populations may be considered, but the existence of or opportunities for connecting multiple sites across a watershed or aquatic system is ideal.

5. Populations of native turtles at the edge of their known or suspected range; these populations may have only a few individuals, but protection throughout the entire range of these animals is important for their conservation and may be prioritized. 